\title{
Thermodynamic and Aerosol Controls in Southeast Pacific Stratocumulus
}

\author{
DAVID B. MECHEM \\ Atmospheric Science Program, Department of Geography, University of Kansas, Lawrence, Kansas \\ SANDRA E. YUTER \\ Department of Marine, Earth, and Atmospheric Sciences, North Carolina State University, Raleigh, North Carolina \\ SIMON P. DE SZOEKE \\ College of Oceanic and Atmospheric Sciences, Oregon State University, Corvallis, Oregon
}

(Manuscript received 20 June 2011, in final form 20 November 2011)

\begin{abstract}
A near-large-eddy simulation approach with size-revolving (bin) microphysics is employed to evaluate the relative sensitivity of southeast Pacific marine boundary layer cloud properties to thermodynamic and aerosol parameters. Simulations are based on a heavily drizzling cloud system observed by the NOAA ship Ronald $H$. Brown during the Variability of the American Monsoon Systems (VAMOS) Ocean-Cloud-Atmosphere-Land Study-Regional Experiment (VOCALS-Rex) field campaign. A suite of numerical experiments examines the sensitivity of drizzle to variations in boundary layer depth and cloud condensation nuclei (CCN) concentration in a manner consistent with the variability of those parameters observed during VOCALS-Rex. All four simulations produce cellular structures and turbulence characteristics of a circulation driven predominantly in a bottom-up fashion. The cloud and subcloud layers are coupled by strong convective updrafts that provide moisture to the cloud layer. Distributions of reflectivity calculated from model droplet spectra agree well with reflectivity distributions from the 5-cm-wavelength scanning radar aboard the ship, and the statistical behavior of cells over the course of the simulation is similar to that documented in previous studies of southeast Pacific stratocumulus. The simulations suggest that increased aerosol concentration delays the onset of drizzle, whereas changes in the boundary layer height are more important in modulating drizzle intensity.
\end{abstract}

\section{Introduction}

Recent studies have focused on the representation of low clouds as a critical component leading to uncertainties in climate change projections simulated by large-scale models (Bony and Dufresne 2005; Medeiros et al. 2008). The climatological importance of large areas of marine boundary layer clouds over the eastern subtropical oceans is well known (Klein and Hartmann 1993). The sensitivity of the global radiation budget to joint interactions of low clouds and aerosol has traditionally been cast into the conceptual framework of the albedo (Twomey 1974, 1977) and cloud lifetime (Albrecht 1989) indirect effects.

Corresponding author address: David B. Mechem, Atmospheric Science Program, Department of Geography, University of Kansas, 1475 Jayhawk Blvd., 213 Lindley Hall, Lawrence, KS 660457613.

E-mail: dmechem@ku.edu
Some progress has been made in observationally quantifying the Twomey effect (e.g., Feingold et al. 2003, 2006), although care is required in constraining the analysis for constant liquid water path (LWP). Quantifying the second indirect effect has proved more problematic because of the complicated and poorly understood feedbacks among aerosol, cloud, and precipitation processes. This study focuses on a subset of low clouds, marine stratocumulus clouds, which are climatologically important (Klein and Hartmann 1993; Bony and Dufresne 2005) and also difficult for current global climate models to represent correctly (Wyant et al. 2010).

Although often thought of as horizontally homogeneous, marine stratocumulus cloud properties are, in reality, highly variable in space and time. Particularly noticeable are pockets of open cells (POCs; Stevens et al. 2005b), which are regions characterized by anomalously low aerosol concentration, low cloud fraction, and cells of small area with high precipitation rates 
$\left(\geq 20 \mathrm{~mm} \mathrm{day}{ }^{-1}\right)$. Collection of cloud droplets associated with the precipitation process reduces the total droplet number, and ultimately cloud condensation nuclei (CCN) (Hudson 1993; Garrett and Hobbs 1995; Feingold et al. 1996; Mechem et al. 2006; Wood 2006). Work employing numerical models has suggested the conceptual model of a positive feedback loop, whereby drizzle scavenges $\mathrm{CCN}$, leading to enhanced drizzle production, which further scavenges $\mathrm{CCN}$ (Feingold and Kreidenweis 2002). Conceptual models have generally assumed a number of dynamical feedbacks that can ultimately lead to cloud thinning and cloud field breakup (Albrecht 1989; Paluch and Lenschow 1991), with recent modeling studies suggesting the presence of precipitation as one mechanism leading to the formation of POCs (Savic-Jovcic and Stevens 2008; Wang and Feingold 2009a,b). Precipitation, however, is not always accompanied by reduced cloud fraction (Stevens et al. 1998; Ackerman et al. 2009).

The 2001 East Pacific Investigation of Climate (EPIC) field campaign took place over the southeast Pacific (SEP) region off the coast of South America (Bretherton et al. 2004). The research cruise sailed from the Galapagos to Chile and found that thicker, nocturnal, drizzling clouds were generally associated with more pronounced mesoscale variability relative to their daytime counterparts. Specifically of interest in EPIC were the transition regions between solid stratocumulus and broken cloud fields, as these were thought to denote the focal point for mechanisms important in driving mesoscale variability. Employing data from scanning C-band radar, Comstock et al. $(2005,2007)$ found that the strongest drizzle rates lay at the transitions between closed and open mesoscale cellular POC structures. Individual drizzle cells drew moisture from the surface layer and had lifetimes up to 2 h (Comstock et al. 2005). Mixed-layer budgets calculated from observations during EPIC showed that drizzle has a negligible effect on the mean water budget since most of the drizzle evaporates before reaching the ocean surface (Caldwell et al. 2005). However, by stabilizing the subcloud layer, drizzle promoted decoupling of the cloud and subcloud layers by suppressing turbulent transports below cloud base.

The Variability of the American Monsoon Systems (VAMOS) Ocean-Cloud-Atmosphere-Land StudyRegional Experiment (VOCALS-Rex, which we shall refer to simply as VOCALS from here forward) field campaign took place during October-November 2008. VOCALS was largely driven by the recognition of global climate model (GCM) uncertainties and biases over the tropics and subtropics arising from inadequately representing the coupled atmosphere-ocean-land system. The experiment involved an extensive suite of airborne and ship-based observational platforms in order to characterize the mechanisms that drive the variability in the SEP climate system (Wood et al. 2011).

During VOCALS, the National Oceanic and Atmospheric Administration (NOAA) ship Ronald H. Brown $(R H B)$ was equipped with remote sensing instruments capable of characterizing cloud, precipitation, and atmospheric properties. A scanning C-band $(5-\mathrm{cm})$ radar sampled the three-dimensional radar reflectivity and radial velocity structures of the drizzle field within a $60-\mathrm{km}$ radius from the ship, and a profiling $35-\mathrm{GHz}$ Doppler cloud radar observed the cloud field just above the ship. The scanning 5-cm radar has been shown to be highly useful for documenting the 3D spatial structure and temporal evolution of the drizzle field (Yuter et al. 2000; Comstock et al. 2005, 2007).

One unexpected and significant finding from the Cband radar aboard ship during VOCALS was the occasional occurrence of echo regions with radar reflectivity greater than $30 \mathrm{~dB} Z$. The reflectivity values were unusually high for boundary layer clouds, which tend to have peak reflectivities in the $0-25-\mathrm{dBZ}$ range [see reflectivities in Frisch et al. (1995)—Atlantic Stratocumulus Transition Experiment (ASTEX), northeast Atlantic; Stevens et al. (2003) — the Second Dynamics and Chemistry of Marine Stratocumulus field study (DYCOMS-II), northeast Pacific; and Bretherton et al. (2004)_EPIC and SEP]. Figure 1 illustrates an example that includes one of these unusually strong precipitation cells. Infrared satellite imagery indicates the radar sampled a region of transition from solid to broken cloud (Figs. 1a,b). The vertical cross section [range-height indicator (RHI)] in Fig. 1c taken to the northeast of the radar indicates drizzle cells with a maximum reflectivity of about $20 \mathrm{dBZ}$. A line of large reflectivities was located to the southwest of the ship, with the vertical cross section indicating reflectivity values over $35 \mathrm{~dB} Z$. The echo top reached nearly $2 \mathrm{~km}$ in altitude, and its shape suggested an updraft penetrating into the inversion zone.

What is the explanation for these large radar reflectivities? Numerical simulations based on one of the VOCALS research flights found that drizzle and POC formation were more sensitive to boundary layer moisture and temperature perturbations than to aerosol number concentration (Wang et al. 2010). A comparison of inversion height $z_{i}$ and water vapor mixing ratio (averaged over the lowest $200 \mathrm{~m}$ ) calculated from the $R H B$ soundings, stratified by broad drizzle rate categories, suggests that drizzle rates tend to be maximized for boundary layer thermodynamic conditions that are moister and deeper (Fig. 2). This perspective is consistent with observations from the NOAA Earth System Research Laboratory (ESRL) profiling 35-GHz cloud 

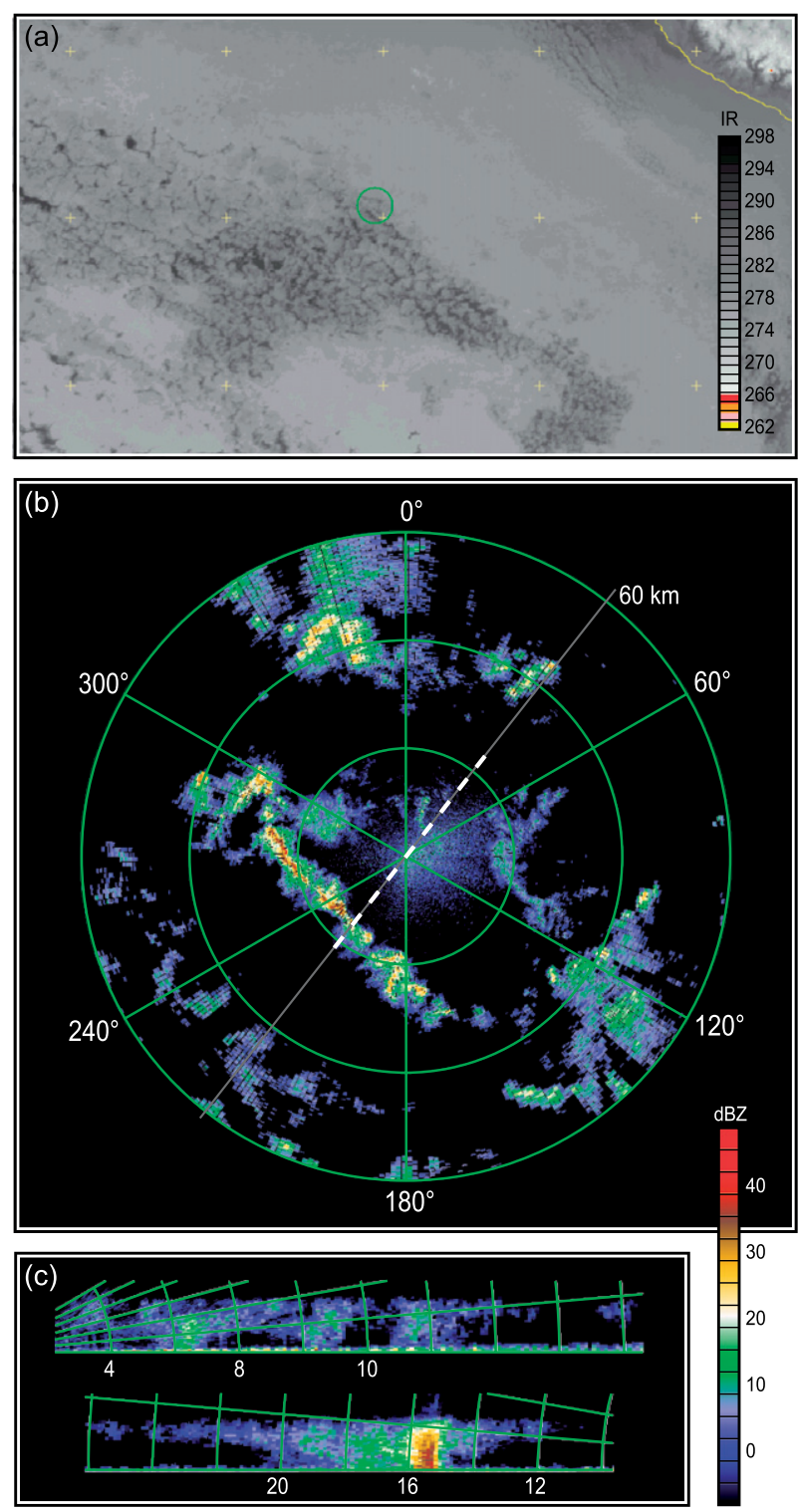

FIG. 1. Satellite and radar view of VOCALS cloud regime transition. (a) Infrared satellite imagery. The green circle represents radar coverage of the $R H B$. (b) Plan view of radar reflectivity from the $1.0^{\circ}$ elevation scan of the C-band radar aboard the RHB. (c) Vertical cross sections (RHIs) taken to the northeast and southwest of the $R H B$, as indicated by the dashed line in (b).

radar aboard the $R H B$, which indicates that heavier precipitation is associated with deeper boundary layers and thicker clouds [see Fig. 2 in de Szoeke et al. (2010b)]. Although the concentration of $\mathrm{CCN}$ observed by the ship is weakly correlated with drizzle rate (Fig. 3) for weak and intermediate cases, the strong drizzle cases were accompanied both low and high concentrations of $\mathrm{CCN}$. All other conditions being equal, lower CCN concentrations should favor stronger drizzle. Although the observations suggest that factors apart from $\mathrm{CCN}$

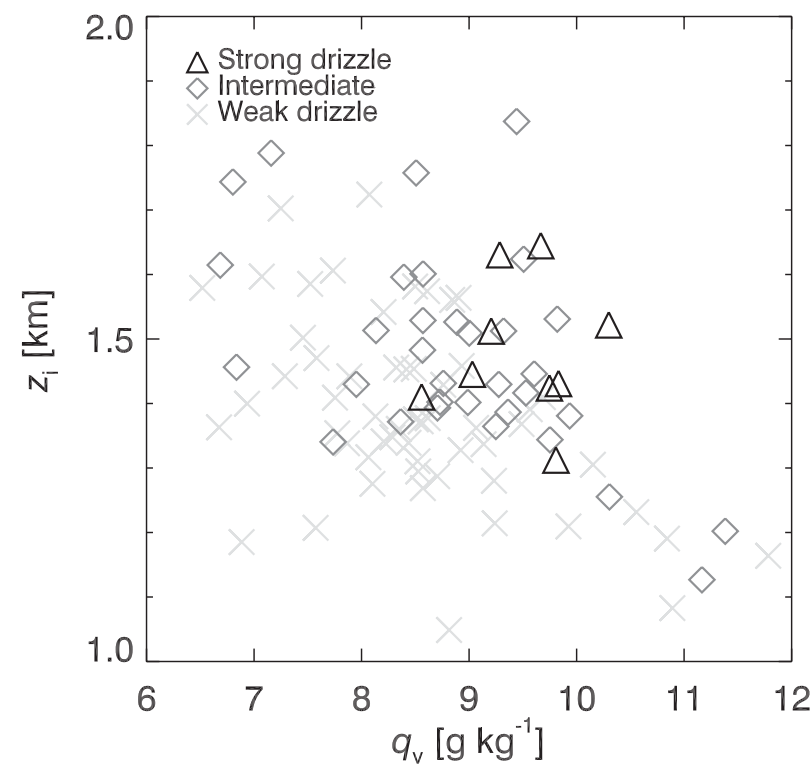

FIG. 2. Boundary layer depth $z_{i}$ as a function of mean (surface to $200 \mathrm{~m}$ ) water vapor mixing ratio $q_{v}$ for the $R H B$ soundings coinciding with drizzle occurrence in the radar sampling volume. Soundings are stratified according to weak, intermediate, and strong drizzle. Any detected meteorological echo (i.e., not sea clutter) $<20 \mathrm{dBZ}$ is termed weak drizzle. Intermediate drizzle contains at least some pixels $\geq 20 \mathrm{dBZ}$. Periods of strong drizzle contain at least 45 pixels $\geq 30 \mathrm{~dB} Z$ that last for at least $30 \mathrm{~min}$.

tend to dominate the precipitation process, we acknowledge that the $\mathrm{CCN}$ measurements at the surface may not be entirely representative of those at cloud base, particularly in cases where substantial evaporation of precipitation can lead to a strong vertical gradient in $\mathrm{CCN}$ concentration. Figures 2 and 3 thus serve to motivate the research; more observational evidence would be required

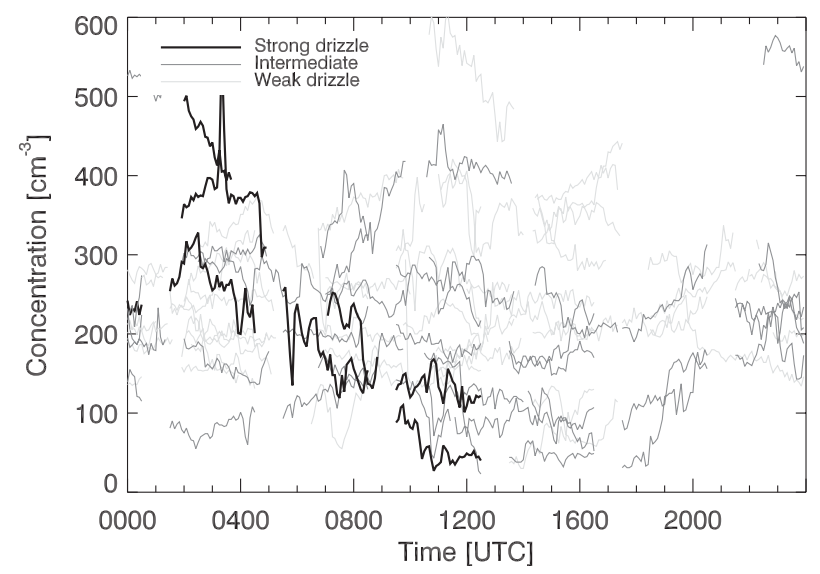

FIG. 3. RHB observations of $\mathrm{CCN}$ concentration $(S=0.6 \%)$, stratified according to drizzle regime as in Fig. 2. Each trace corresponds to $\pm 1.5 \mathrm{~h}$ from a sounding time. (CCN data courtesy Dave Covert, University of Washington). 
to demonstrate concretely the relationship between drizzle and cloud-level CCN.

Both the thermodynamic analysis and the cloud radar data suggest a robust relationship among boundary layer depth (likely modulated by entrainment processes and large-scale vertical velocity) and cloud thickness and precipitation. The large-scale vertical velocity over the southeast Pacific is predominantly subsidence, with a superimposed "upsidence wave" (Garreaud and Muñoz 2004) arising from a gravity wave response to the diurnal heating of the continent. The upsidence wave response is complicated and depends on longitude [e.g., Fig. 5a in Wood et al. (2009)], but it is largely in phase with the diurnal cycle of cloud thickness over the SEP. Caldwell and Bretherton (2009), however, found in multiday simulations of the EPIC cruise that the diurnal cycle of largescale vertical velocity (mostly subsidence) played little role in modulating the LWP, suggesting that the diurnal variability in radiative fluxes overwhelmed the effects of the upsidence wave.

This paper employs a numerical simulation framework to explore the hypothesis that natural variability in boundary layer thermodynamic properties exerts a greater influence on cloud and precipitation processes than does variability in aerosol concentrations. We do this by varying the thermodynamic and aerosol properties in a way consistent with the environmental variability measured over the two $R H B$ ship cruises during the VOCALS campaign (de Szoeke et al. 2010b). Because of the complexities involved in longer-term feedbacks, our focus is on primary cloud and precipitation responses that occur over the time frame from 8 to $12 \mathrm{~h}$ of the simulation.

\section{Methodology}

Results from EPIC and preliminary analysis of the VOCALS observations demonstrate that precipitation and mesoscale organization go hand in hand. This suggests that the traditional small-domain large-eddy simulation (LES) approach is insufficient for representing the mesoscale aspects of the cloud organization and precipitation processes. Relatively few studies capture with any fidelity both boundary layer turbulence and mesoscale circulation, although the recent trend has been toward employing larger and larger domains in order to capture mesoscale aspects of the circulation. Xue et al. (2008) employed a $12.4 \times 12.4 \mathrm{~km}^{2}$ domain and found a relationship between precipitation-driven outflow and open cells accompanying trade wind cumulus. Savic-Jovcic and Stevens (2008) used typical LES grid spacings (35 $\mathrm{m}$ in the horizontal) over a somewhat larger domain of size $25.6 \times 25.6 \mathrm{~km}^{2}$, whereas Wang and Feingold (2009a,b) coarsened the grid spacing to $300 \mathrm{~m}$ in order to run over a significantly larger $(60 \times$ $60 \mathrm{~km}^{2}$ ) domain. The trend in these studies has been to recognize that the turbulent flow and the mesoscale variability must both be accounted for in order to attain a faithful representation of boundary layer cloud structures and evolution.

\section{a. Near-LES numerical framework}

In the spirit of these recent studies, we employ the numerical framework of "near-LES," the aim being to conduct simulations with a large enough domain to capture mesoscale structures but at sufficient resolution to adequately represent the turbulent boundary layer fluxes. This approach is also known as very-large-eddy simulation (VLES), particularly in the engineering disciplines. Our simulations use the System for Atmospheric Modeling-Explicit Microphysics (SAMEX). The dynamical core is based on the System for Atmospheric Modeling (SAM; Khairoutdinov and Randall 2003), a model based on an anelastic equation set and monotonic, positive-definite advection for scalar quantities (Smolarkiewicz and Grabowski 1990). SAMEX is applied in the near-LES mode described above. For these simulations, SAMEX employs a horizontal grid spacing of $150 \mathrm{~m}$. The vertical mesh is stretched, with grid spacing ranging from $25 \mathrm{~m}$ near the surface and the inversion, with larger values between. At these grid spacings, the near-LES runs with domain size $57.6 \times$ $57.6 \mathrm{~km}^{2}$ capture the mesoscale variability reasonably well. This experimental setup is employed as a starting point for the simulation suite.

Previous studies (Bretherton et al. 1999; Stevens et al. 2005a) emphasized the importance of resolving the entrainment zone, and the fact that the vertical grid spacing should be $O(5 \mathrm{~m})$ in order to represent entrainment correctly. Because our simulations are outside the realm of true LES, we are particularly concerned about adequately representing the entrainment process. The model subgrid-scale (SGS) parameterization is that of Deardorff (1980), with the SGS grid length taken to be the local vertical grid spacing, as in Khairoutdinov and Randall (2003). While we acknowledge the limitations of 25-m vertical grid spacing, we have found that indirect measures of entrainment rates, such as being able to predict reasonable cloud LWP values and the behavior of the smaller-scale cloud processes in our simulations, compare well to a traditional high-resolution LES of the same case.

SAMEX employs explicit microphysics (Kogan 1991), which represent both droplets and $\mathrm{CCN}$ in a size-resolving framework. Simulations were conducted with 34 droplet bins and $19 \mathrm{CCN}$ bins. The number of bins is based on 


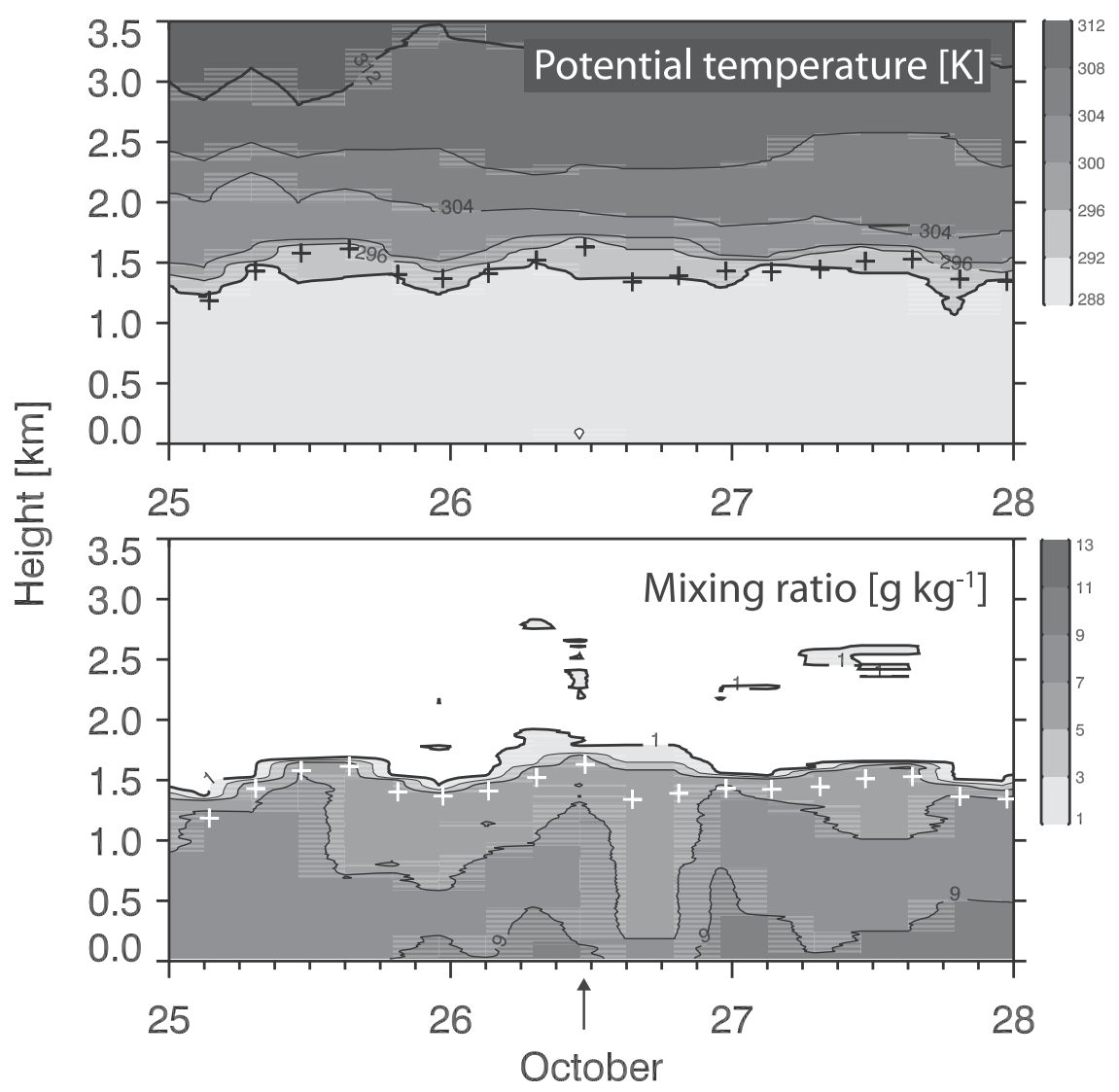

FIG. 4. Time-height evolution of (top) potential temperature $\theta$ and (bottom) water vapor mixing ratio for 26-28 Oct 2008. The arrow below the $x$ axis of the bottom panel indicates the time of the sounding used to initialize the simulations.

simulations from the Rain in Cumulus over the Ocean (RICO) trade cumulus intercomparison (van Zanten et al. 2011). The strong drizzle cases in VOCALS benefit from the relatively large number of droplet bins (34), compared to previous simulations of stratocumulus, which employed 25 bins. (Kogan et al. 1995; Khairoutdinov and Kogan 1999). Although computationally expensive, bin microphysics assures the best possible fidelity for aerosolcloud-precipitation interactions, as well as for calculations such as reflectivity.

\section{b. Initial conditions and forcing}

Our simulations are centered around the heavy precipitation features present in the RHB C-band radar from 1100 to 1300 UTC 26 Oct 2008 (Fig. 1). Soundings from the $R H B$ taken over a 3-day period indicate a boundary layer with mean depth $z_{i}$ of $1440 \mathrm{~m}$ that ranges in depth from 1185 to $1631 \mathrm{~m}$ (Fig. 4). Although the boundary layer depth varies, the stability of the inversion layer changes little over the course of the 3 days. Free-tropospheric humidity is very low, less than $1 \mathrm{~g} \mathrm{~kg}^{-1}$. Periods of large $z_{i}$ tend to be associated with cooler and sometimes moister boundary layers, which we suspect arise from evaporating drizzle. The boundary layer during the period of interest is anomalously deep $\left(z_{i} \approx 1650 \mathrm{~m}\right)$ and moist, with a surface $q_{v}$ of greater than $10 \mathrm{~g} \mathrm{~kg}^{-1}$.

Model initial conditions are based on the 1100 UTC 26 October 2008 sounding from the RHB. This sounding

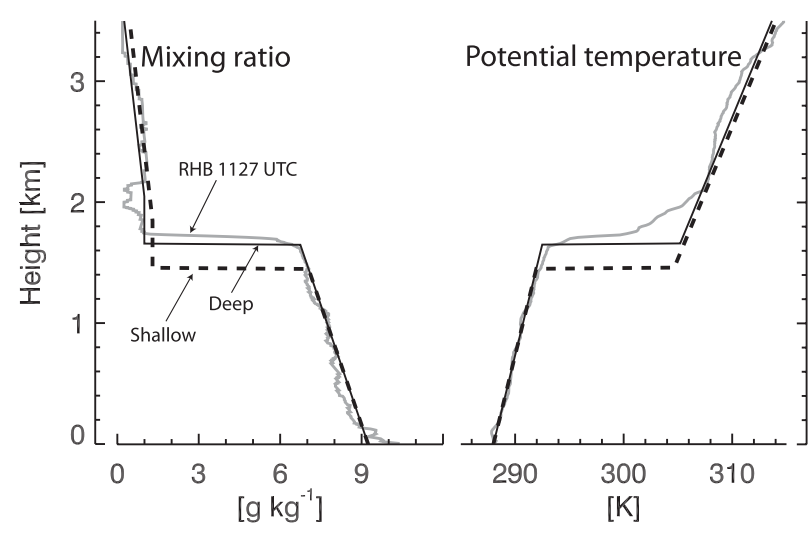

FIG. 5. Idealized soundings overlaid on the 1100 UTC 26 Oct 2008 $R H B$ sounding. 
(Fig. 5) indicates a boundary layer approximately $1650 \mathrm{~m}$ deep with a potential temperature jump $\Delta \theta=12.7 \mathrm{~K}$ and a moisture jump $\Delta q_{v}=-8.25 \mathrm{~g} \mathrm{~kg}^{-1}$. In contrast to typical stratocumulus cases with well-mixed boundary layers, this VOCALS sounding is highly stratified. Because this sounding is associated with periods of large precipitation rates, this stratification may partly be a result of the precipitation process acting to stably stratify the boundary layer (Stevens et al.1998). The model initial profiles are constructed as a simple piecewise-linear fit to the observed profiles (Fig. 5). This piecewise-linear fit is responsible for the slight difference in boundary layer depth between the sounding $(1631 \mathrm{~m})$ and that used in the simulations $(1650 \mathrm{~m})$.

Simulations assume only longwave radiation is active (nocturnal conditions), and for reasons of computational expense we employ the simple longwave treatment based on liquid water path previously employed in Stevens et al. (2005a) and Ackerman et al. (2009). Although this treatment of radiation is highly idealized, it nevertheless is remarkably accurate, assuming it is calibrated for the specific case (Larson et al. 2007). Although the simple approach neglects clear-sky radiative cooling, which has been found to be important in boundary layer open cells (Wang and Feingold 2009a,b), the high cloud fraction of this case $(>0.89)$ justifies its use here.

Parameters for the radiation scheme were evaluated by applying the $\delta$-four-stream radiative transfer method of Fu and Liou $(1992,1993)$ to the 1100 UTC sounding. In addition to the sounding, we assumed a simple adiabatic liquid water profile with a maximum LWC of $0.5 \mathrm{~g} \mathrm{~m}^{-3}$ at a height of $1.65 \mathrm{~km}$. Calculations of net radiative flux across the boundary layer are for the most part insensitive to this rather arbitrary choice of maximum LWC. These calculations resulted in an estimate of $105 \mathrm{~W} \mathrm{~m}^{-2}$ of cooling across cloud top and $25 \mathrm{~W} \mathrm{~m}^{-2}$ of warming across cloud base, or a net flux of $80 \mathrm{~W} \mathrm{~m}^{-2}$ across the boundary layer depth. This large radiative flux reflects the dryness of the free troposphere and is one distinguishing characteristic of boundary layer cloudiness over the VOCALS region, a result consistent with aircraft observations of $91 \mathrm{~W} \mathrm{~m}^{-2}$ in overcast regions (Wood et al. 2011). We projected the cloud-base and cloud-top fluxes onto a single value of $80 \mathrm{~W} \mathrm{~m}^{-2}$ applied at cloud top. Stevens et al. (2005a) argued that simulations employing this simplification differed little from those employing separately the cloud-top cooling and cloud-base warming terms.

The bin microphysical parameterization requires initial conditions for $\mathrm{CCN}$. We assumed a $\mathrm{CCN}$ concentration of $135 \mathrm{~cm}^{-3}$, which we obtained from an average of $R H B$ CCN measurements ( $0.6 \%$ supersaturation) over the 0700-1700 UTC period (D. Covert 1999, personal communication). Without having detailed size information, we assume a $\mathrm{CCN}$ size distribution follows the same shape as the lognormal spectrum used in the RICO intercomparison (van Zanten et al. 2011). Future simulations may take advantage of $\mathrm{CCN}$ activation spectra calculated from concentration measurements taken at various magnitudes of supersaturation. The $\mathrm{CCN}$ particles were assumed to be completely soluble and composed of sodium chloride. Although it is likely the observed $\mathrm{CCN}$ were some combination of sodium chloride and ammonium sulfate, the model is not particularly sensitive to this assumption of composition.

Surface fluxes of heat, moisture, and momentum are evaluated via a bulk aerodynamic framework and calculated using the ocean-relative winds. Sea surface temperature (SST) is assumed to be $291.4 \mathrm{~K}$. These assumptions result in fluxes of $4-8 \mathrm{~W} \mathrm{~m}^{-2}$ for sensible heat and $55-70 \mathrm{~W} \mathrm{~m}^{-2}$ for latent heat. The latent heat flux produced in the simulations is somewhat smaller than both the observed value of $95 \mathrm{~W} \mathrm{~m}^{-2}$ and the climatological estimate of $60-100 \mathrm{~W} \mathrm{~m}^{-2}$ calculated from a synthesis of field campaigns over the SEP (de Szoeke et al. 2010a). We suspect the evaporation of strong precipitation in the simulation moistens the surface layer and reduces the moisture flux, relative to the SEP climatology, but the discrepancy between the model and surface latent heat flux for this particular case is puzzling. Strong evaporation leading to an underestimate of latent heat flux would also produce an overestimation of sensible heat flux. However, in our simulations sensible heat flux is underestimated as well (observed sensible heat flux value of $15 \mathrm{~W} \mathrm{~m}^{-2}$ ). The underestimates in the fluxes are consistent with a slight underestimate in surface winds produced by the model $\left(5.3 \mathrm{~m} \mathrm{~s}^{-1}\right.$ in the model vs $7.8 \mathrm{~m} \mathrm{~s}^{-1}$ in the observations).

A time-independent profile of large-scale vertical motion (subsidence divergence) is imposed throughout the simulation. Vertical velocity $w_{\mathrm{ls}}$ is zero at the surface and decreases linearly to a value of $-0.165 \mathrm{~cm} \mathrm{~s}^{-1}$ at an altitude of $1.65 \mathrm{~km}$ and above. This vertical velocity profile was derived from the $850-\mathrm{mb}$ vertical motion field in National Centers for Environmental Prediction (NCEP) analysis, averaged over the course of the day and over a domain ranging from $87^{\circ}$ to $83^{\circ} \mathrm{W}$ in longitude and from $22^{\circ}$ to $18^{\circ} \mathrm{S}$ in latitude. Although the location in the vicinity of $85^{\circ} \mathrm{W}$ experiences noticeable day-to-day variability in subsidence, its remote location relative to the continent minimizes the influence of the upsidence wave (Garreaud and Muñoz 2004; Wood et al. 2009).

\section{c. Sensitivity experiments}

A significant advantage of a numerical modeling approach is the ability to isolate the effects of specific factors 

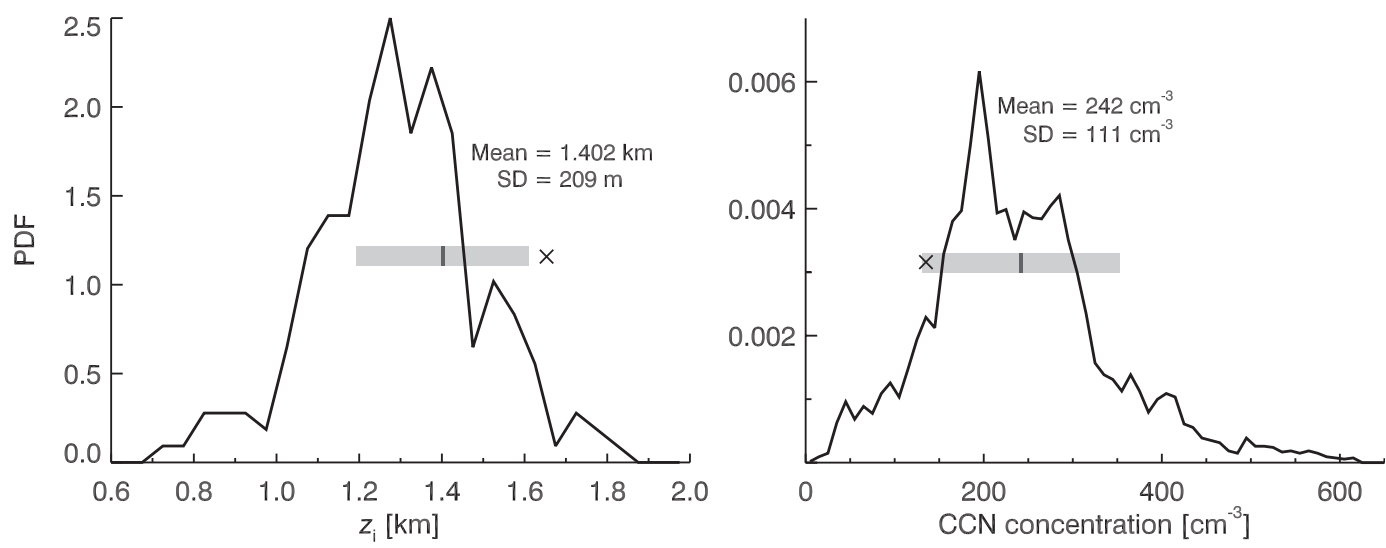

FIG. 6. PDFs of the inversion height $z_{i}$ and $\mathrm{CCN}$ concentration $(S=0.6 \%)$ The " $\times$ " symbols represent the inversion height and $\mathrm{CCN}$ concentration of the Deep (control) simulation.

or combinations of factors via sensitivity experiments, where different factors are varied from a control simulation. We test our hypothesis ("Natural variability in boundary-layer thermodynamic properties exerts a greater influence in cloud and precipitation processes than does variability in aerosol concentrations.") using this approach, isolating the effects of boundary layer depth and CCN concentration. We vary these two quantities based on the variability of these factors observed during the VOCALS cruises. Constraining these quantities according to natural variability serves to assess the relative importance of the two factors.

From the point of view of variability over the course of the entire VOCALS project, boundary layer depth and $\mathrm{CCN}$ concentrations at the 1100 UTC sounding time are deeper and cleaner than average (Fig. 6). In one simulation (termed "Shallow"), we decrease the boundary layer depth by $200 \mathrm{~m}$, corresponding approximately to a $1 \sigma$ decrease in the inversion height probability distribution function (PDF) (Fig. 6). In a similar fashion, we perform a simulation ("Doubled CCN") in which CCN concentration is doubled from 135 to $270 \mathrm{~cm}^{-3}$, again corresponding approximately to a $1 \sigma$ increase.

Owing to the likelihood of mutual interactions between the two factors, sensitivity experiments varying both factors are performed. From a dynamical systems standpoint, this is an important additional step, since it is unknown whether these combined interactions are simply additive in nature, whether they tend to cancel, or whether variations in multiple factors result in interactions that are nonlinear and unpredictable. Following the factor separation method described in Stein and Alpert (1993) and Dearden (2009), we perform an additional simulation ("Shallow + Doubled CCN"), which takes into account the mutual interactions between these two factors.

\section{Results}

All four simulations were run for $18 \mathrm{~h}$. In this paper, we concentrate our analysis on the period from 8 to $12 \mathrm{~h}$ in order to focus on what we term the primary microphysicaldynamical responses. Time series over longer periods give evidence of complicated feedbacks, which are beyond the scope of our study. To spin up boundary layer turbulent flow, collision-coalescence was turned off for the first $6 \mathrm{~h}$ of the simulation.

Over the period from $8-12 \mathrm{~h}$, the cloud system in the control simulation begins as an unbroken, relatively homogeneous cloud deck and develops a substantial degree of mesoscale structure, characterized by large drizzle cells of order $100 \mathrm{~km}^{2}$. Figure 7 shows an example of these drizzle cells, indicated by the maximum reflectivity in each column (composite reflectivity). Reflectivity is calculated using the entire drop size distribution available from the model.

A vertical cross section through one of these mesoscale drizzle cells (Fig. 7b) is reminiscent of organized deep convective structures (e.g., Zipser 1977; Houze et al. 1989). The region of strongest precipitation in the cell (at $X=28 \mathrm{~km}$ ) is associated with a tilted updraft structure ranging from the surface to the top of the boundary layer, and downdraft in the precipitation core itself at levels below $0.6 \mathrm{~km}$. The regions of weaker precipitation to the east are also downdraft-dominated. Despite continuous radiative forcing in the form of cloud-top cooling, vertical motion in the overhanging "anvil" cloud, at least in this particular cross section, is weak. The simulated radar image suggests that strong, penetrative updrafts associated with individual drizzle cells are evidently acting as a substantial moisture source for the stratocumulus cloud layer. In fact, it appears that liquid water detraining from these strong but relatively isolated updrafts is the predominant 

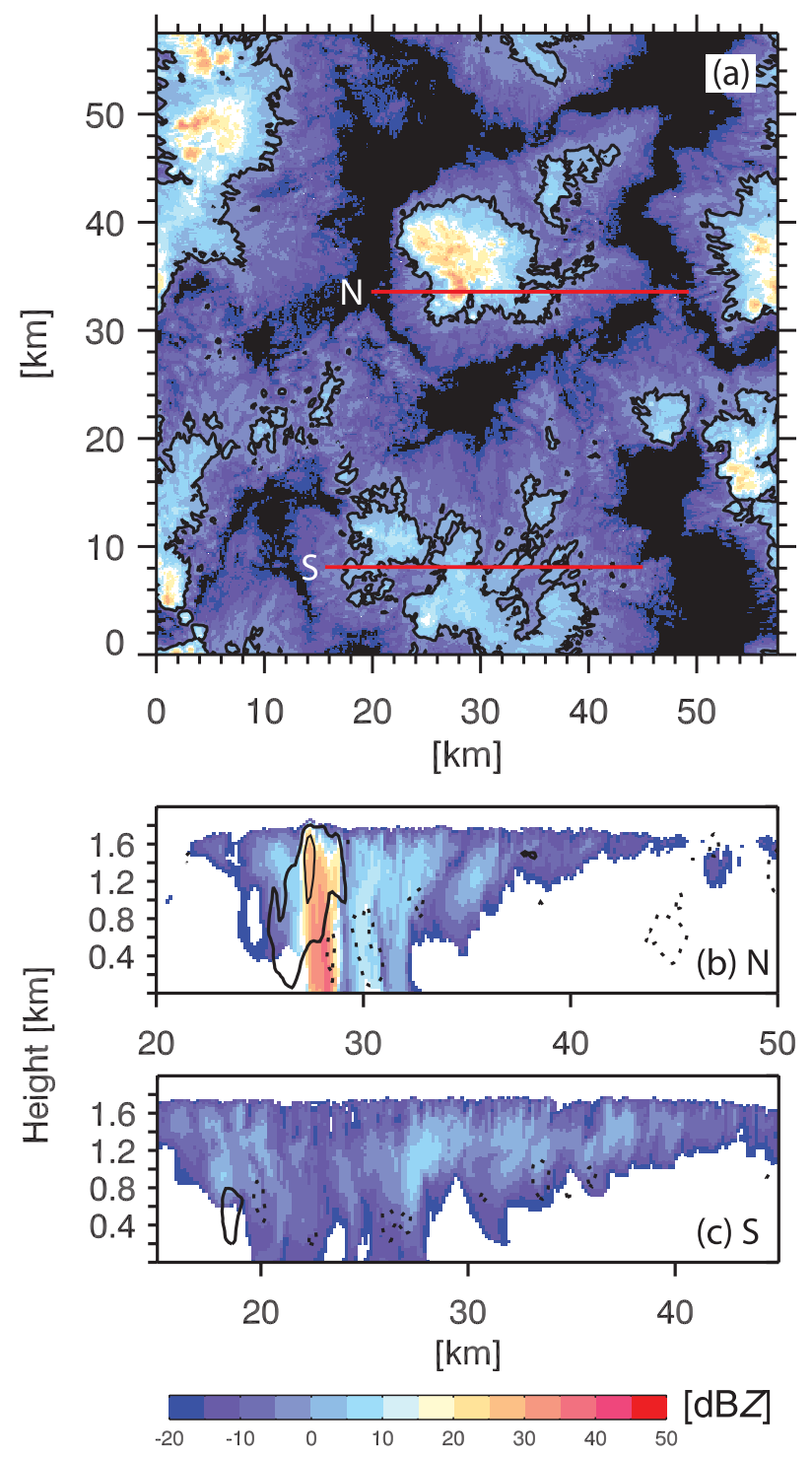

FIG. 7. Model reflectivity at $12 \mathrm{~h}$ for the control simulation. (a) Composite reflectivity. Thick black contours are through $0 \mathrm{dBZ}$ points and roughly represent the sensitivity of the $R H B$ C-band radar. (b),(c) Vertical cross sections of reflectivity and vertical velocity through the red lines in (a). Contours represent vertical velocity values of $-2.5,-0.5,0.5$, and $2.5 \mathrm{~m} \mathrm{~s}^{-1}$, with dashed contours representing negative values.

factor maintaining the stratocumulus cloud deck. These cloud structures bear significant resemblance to those in the Atlantic Trade Wind Experiment (ATEX) model intercomparison (Stevens et al. 2001), in which trade cumulus detraining at the inversion serves to maintain the stratocumulus layer.

\section{a. Mean simulation behavior}

Time series over a 4-h period indicate marked differences among the four simulations (Fig. 8). Precipitation
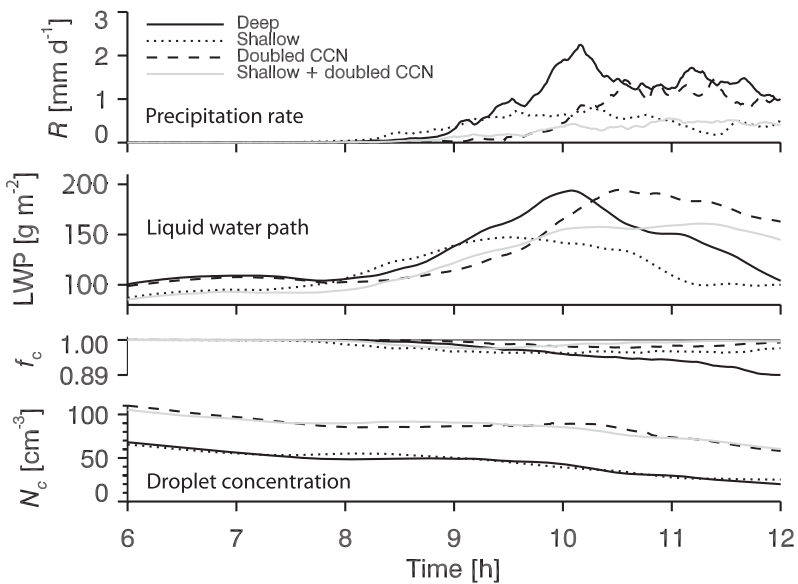

FIG. 8. Time series of surface precipitation rate $R$, liquid water path, cloud fraction, and droplet concentration.

rates $R$ are highly variable, with the Deep (control) simulation having the largest rate and the Shallow + Doubled CCN simulation having the smallest. Although the time series are noisy, $R$ for the Doubled CCN simulation is larger than for the Shallow simulation, indicating that a reduction in boundary layer depth exerts more of an impact on precipitation outcomes than does a typically observed increase in CCN. Early in the simulation (8-9 h), precipitation rate and LWP in the Shallow simulation are larger than in the Deep case. We speculate this behavior is associated with the slightly greater precipitation produced early in the Deep simulation and the subsequent stabilization of the boundary layer, which serves as a brake on turbulent kinetic energy (TKE) production.

LWP slightly leads the precipitation rate, which implicates LWP as a primary driver in the precipitation process. In each simulation, the LWP increases for a time, followed by a leveling off or a decrease that appears to coincide with a precipitation rate threshold, different for each simulation. The temporal behavior of LWC is complicated, however, because it not only acts as a control on drizzle production but also is strongly affected by drizzle (via sedimentation and dynamical feedback on the entrainment rate). Cloud fraction $f_{c}$ is smallest in the most strongly precipitating (Deep) case but nevertheless remains high $(\sim 0.89)$. In the other four simulations, $f_{c}$ remains above 0.96 , indicating a persistent deck of stratocumulus. Droplet concentration $N_{c}$ is initially determined by the CCN concentration. As would be expected, the two simulations with fewer $\mathrm{CCN}$ precipitate more, and hence the fractional reduction of $N_{c}$ with time via coalescence processing is greater (a positive feedback between precipitation rate and $N_{c}$ reduction). Coalescence processing has been shown to be dependent on both precipitation rate and on the 
TABLE 1. Time mean (median in parentheses) of LES precipitation rate, LWP, and cloud fraction, averaged over the 8-12-h period. Entrainment rate is calculated as $w_{e}=d z_{i} / d t-w_{\mathrm{ls}}$, where $z_{i}$ is the inversion height and $w_{\mathrm{ls}}$ is the specified large-scale vertical motion $\left(\mathrm{m} \mathrm{s}^{-1}\right)$ at the inversion.

\begin{tabular}{lcccc}
\hline \hline \multicolumn{1}{c}{ Simulation } & $\begin{array}{c}R \\
\left(\mathrm{~mm} \mathrm{day}^{-1}\right)\end{array}$ & $\begin{array}{c}\text { LWP } \\
\left(\mathrm{g} \mathrm{m}^{-2}\right)\end{array}$ & $f_{c}$ & $\begin{array}{c}w_{e} \\
\left(\mathrm{~cm} \mathrm{~s}^{-1}\right)\end{array}$ \\
\hline Deep & $0.98(1.15)$ & $145(148)$ & $0.96(0.96)$ & 0.76 \\
Shallow & $0.44(0.48)$ & $125(128)$ & $0.97(0.96)$ & 0.58 \\
Doubled CCN & $0.57(0.45)$ & $151(163)$ & $0.99(0.99)$ & 0.85 \\
Shallow + & $0.28(0.31)$ & $139(149)$ & $0.99(0.99)$ & 0.72 \\
$\quad$ Doubled CCN & & & & \\
\hline
\end{tabular}

droplet concentration itself (Mechem et al. 2006; Wood 2006).

Table 1 summarizes the time-mean behavior of these statistics. The precipitation rate is strongest for the Deep simulation. Reducing the boundary layer depth by $200 \mathrm{~m}$ results in $0.54 \mathrm{~mm}$ day $^{-1}$ decrease $(-55 \%)$ in $R$. Doubling the CCN reduces $R$ but not quite so dramatically $\left(-0.41 \mathrm{~mm} \mathrm{day}{ }^{-1}\right.$ or $\left.-42 \%\right)$. Differences in mean LWP between the simulations are not quite as dramatic. Liquid water path is reduced in the Shallow simulation by $14 \%$ and in the Doubled CCN simulation by $4 \%$. Furthermore, differences in LWP between the simulations may partly be an artifact of simply averaging over the last $4 \mathrm{~h}$ of the simulations, rather than choosing caseby-case averaging periods defined by the evolution of the cloud and precipitation fields. Even in the most strongly precipitating case (Deep simulation), the mean cloud fraction remains large, although the time series in Fig. 8 indicates that cloud fraction in the Deep simulation is departing from the ensemble and becoming notably smaller. From what is effectively just a single statistical realization, we are not able to evaluate the statistical significance of these differences.

Entrainment rate $w_{e}$ is generally consistent with LWP and precipitation rate (Table 1 ). This relationship is clearest between the two deep simulations (Deep and Doubled CCN) and between the two shallow simulations (Shallow and Shallow + Doubled CCN). The shallow versus deep simulations have large differences in their baseline thermodynamic and cloud structures. In each set of simulations (i.e., comparing Deep with Doubled CCN, or comparing Shallow with Shallow + Doubled CCN), increased precipitation is associated with decreased liquid water path, reduced cloud fraction, and a smaller entrainment rate. This behavior is consistent with drizzle reducing cloud water (either by sedimentation or by suppressing the vertical transport via stably stratifying the boundary layer), leading to a reduction of radiative cooling at cloud top. Less radiative cooling and less liquid water at cloud top (reducing evaporative enhancement

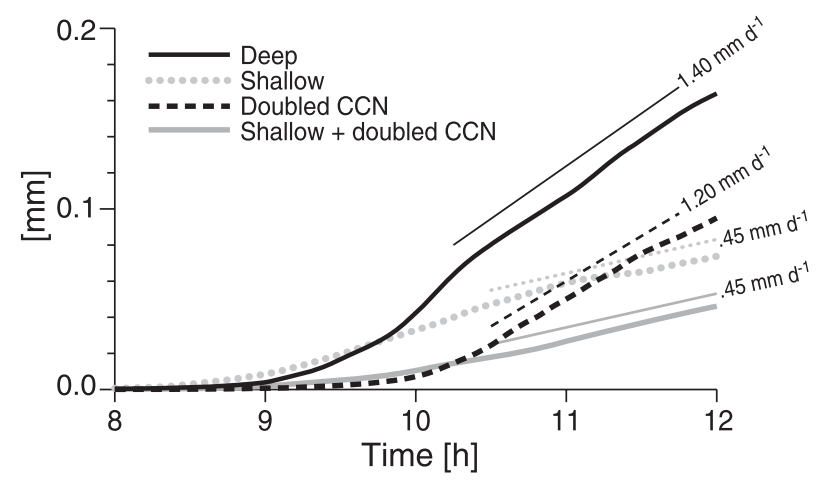

FIG. 9. Time series of accumulated precipitation.

associated with entrainment mixing of free tropospheric and cloudy boundary layer air) can both act to reduce TKE and entrainment. One caveat applies to our approach, and to others that use this near-LES methodology: given our relatively crude approximately $25-\mathrm{m}$ vertical grid spacing near the inversion, we note that $w_{e}$ is most likely overestimated. Entrainment rates during a 6-day period from the EPIC field campaign were estimated to be $0.4 \pm 0.1 \mathrm{~cm} \mathrm{~s}^{-1}$ (Caldwell et al. 2005), although we would expect $w_{e}$ from our nocturnal simulations to perhaps be somewhat larger than the EPIC estimates.

Although precipitation rate most directly corresponds to other boundary layer energetic fluxes (i.e., it can be expressed as watts per square meter), because of its noisiness the accumulated precipitation is often a better statistic to gauge the resulting precipitation behavior. Accumulated precipitation can be plotted as a time series, with the slope of the time series corresponding to the precipitation rate (Fig. 9). This presentation confirms that the Deep case precipitates most strongly, followed by the Doubled CCN, the Shallow, and the simultaneously Shallow + Doubled CCN cases. Separating the cases as above into deep and shallow simulations indicates that the main effect of additional $\mathrm{CCN}$ is to delay the onset of precipitation (as in Stevens and Seifert 2008) but that after a time the precipitation rates for the clean and the doubled CCN simulations are roughly similar. This behavior most likely stems from the increased CCN suppressing the self-collection of small drops into precipitation nuclei. Once a sufficient number of precipitation nuclei are created, however, collection of cloud droplets by these precipitation nuclei can occur just as it does in the cleaner simulation. Profiles of mean precipitation rate (Fig. 10) are consistent with the surface precipitation rate time series but also indicate that precipitation evaporation in the subcloud layer plays a substantial role in influencing surface precipitation. In particular, the low-CCN-concentration simulations experience greater evaporation than simulations with greater $\mathrm{CCN}$ concentration. 


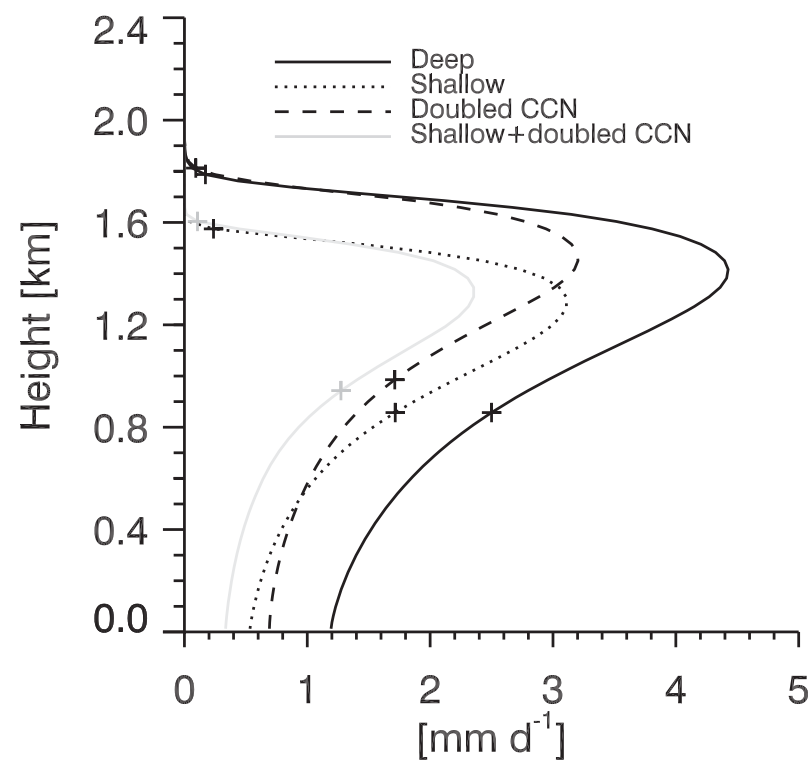

FIG. 10. Mean profiles of precipitation rate. The plus signs represent mean cloud base and cloud top.

The boundary layer is greatly stratified thermodynamically, with a difference in $\theta_{l}$ of about $1.5 \mathrm{~K}$ between the surface and the inversion base (Fig. 11). Moisture is even more stratified, with $q_{t}$ decreasing by about $2.5 \mathrm{~g} \mathrm{~kg}^{-1}$ between the surface and inversion base. Mean cloud base is approximately $450 \mathrm{~m}$ and delineates distinct cloud-layer and subcloud-layer structures. The bulk of the moisture stratification takes place between 450 and $800 \mathrm{~m}$ in the lower part of the cloud layer. The bulk of the cloud layer from $800 \mathrm{~m}$ up to the inversion is reasonably well mixed. The liquid water profiles (cloud water plus precipitation) exhibit peaks in the upper part of the cloud $(\sim 1.65 \mathrm{~km}$ in the Deep simulation), but the peak is not sharp and the profile is far from adiabatic (near linear) with height. The profiles in Fig. 11 suggest substantial differences between this case and idealized, nonprecipitating stratocumulus. In idealized stratocumulus, $\theta_{l}$ and $q_{t}$ are more or less well mixed over the entire boundary layer, and average liquid water $q_{l}$ exhibits a sharp maximum at the inversion base, with a linear decrease below the maximum. Strong precipitation acts to maintain the thermodynamic stratification in Fig. 11 via evaporation of drizzle over the subcloud layer and the resulting net cloud-layer warming proportional to the precipitation rate (Stevens et al. 1998).

Except for the obvious difference in boundary layer depth, visually the $\theta_{l}$ profiles do not differ substantially between the four cases, but calculations confirm that the Deep (control) is the most stable of the profiles $\left(d \theta_{l} / d z=1.65 \mathrm{~K} \mathrm{~km}^{-1}\right.$ for the Deep simulation compared to $1.07 \mathrm{~K} \mathrm{~km}^{-1}$ for the Shallow + Doubled CCN simulation). The stabilizing effects of precipitation are more evident in the $q_{t}$ profiles, with the deeper, more strongly precipitating simulations characterized by a greater difference in $q_{t}$ between inversion base and the surface. Average liquid water in the cloud layer is most strongly affected by changes in $\mathrm{CCN}$, suggesting that $\mathrm{CCN}$ may have more of an impact than PBL depth on cloud optical properties.

Profiles of dynamical quantities (Fig. 12) describe boundary layers with the greatest vertical velocity variance $\overline{w^{\prime} w^{\prime}}$ (i.e., strongest turbulence) lying in the cloud layer. Although the $q_{t}$ profiles in Fig. 11 display evidence of two distinct layers, the vertical velocity variance does not exhibit the double-maximum structure typical of two distinct circulations found in decoupled, radiatively driven stratocumulus.

The two deeper simulations have greater maxima in $\overline{w^{\prime} w^{\prime}}$. For a given boundary layer depth (e.g., comparing the Deep and Doubled CCN simulations), the maximum in $\overline{w^{\prime} w^{\prime}}$ is well correlated with LWP, which is evident comparing the $\overline{w^{\prime} w^{\prime}}$ profiles in Fig. 12 with the $q_{l}$ profiles

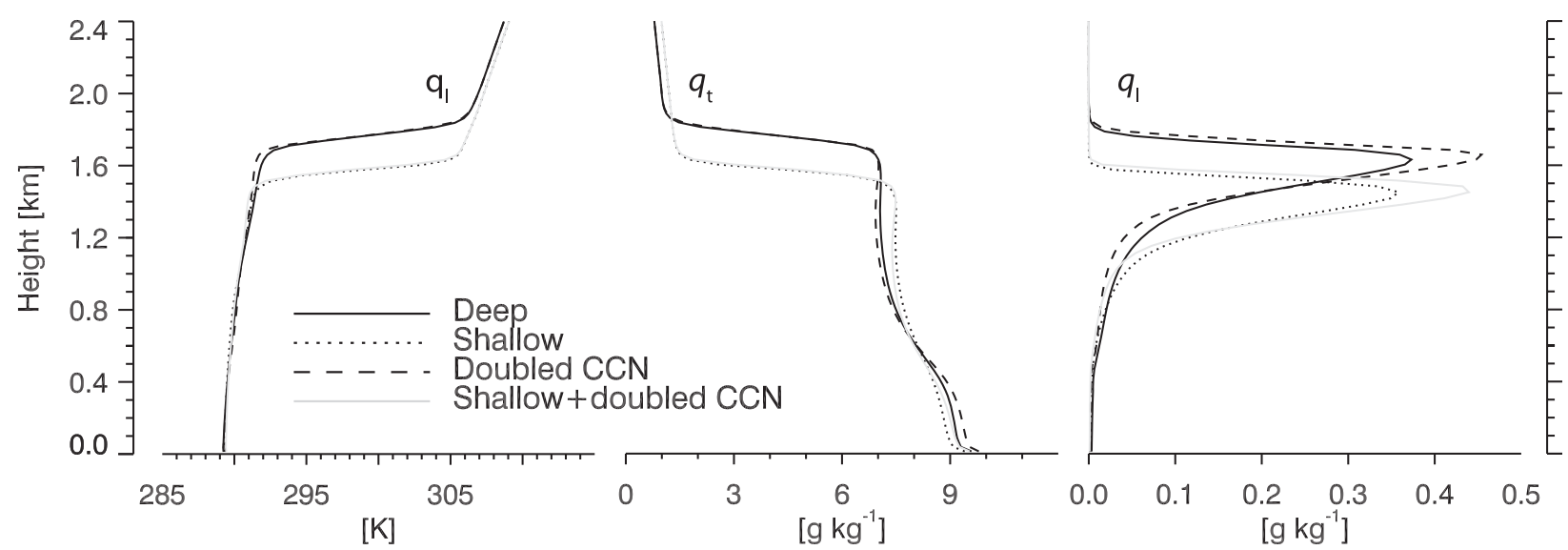

FIG. 11. Mean profiles of liquid water potential temperature $\theta_{l}$, total water mixing ratio $q_{t}$, and liquid water mixing ratio $q_{l}$. 

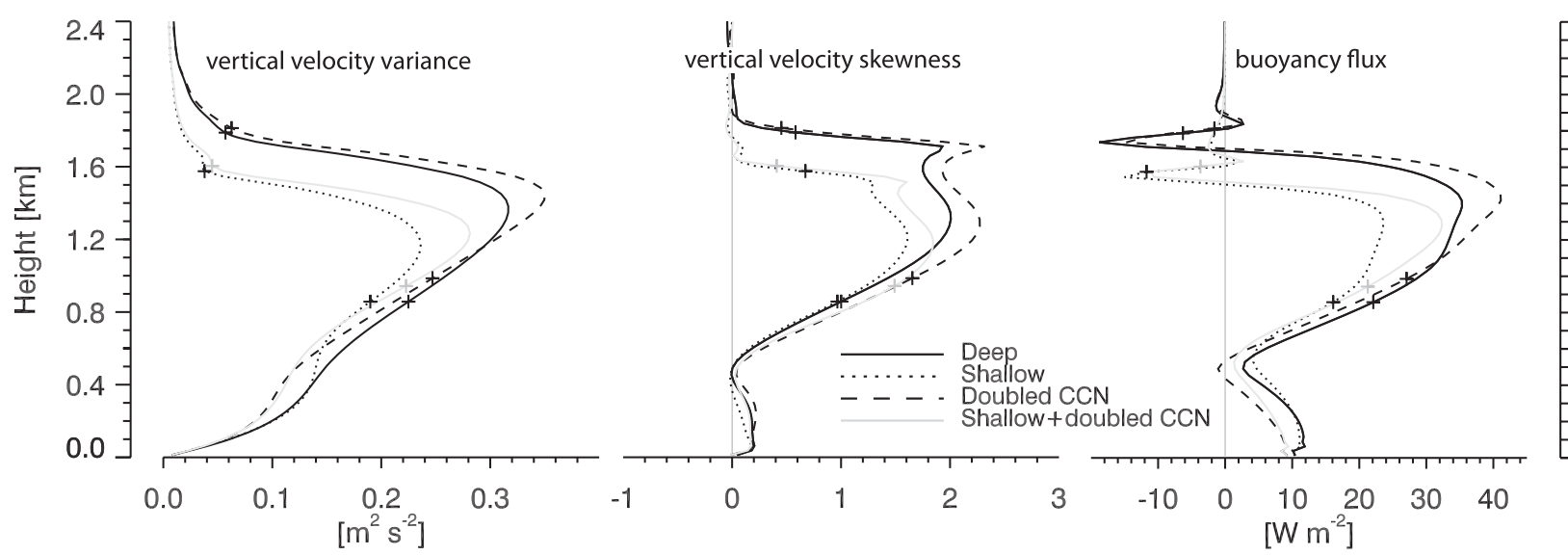

FIG. 12. Mean profiles of vertical velocity variance $\overline{w^{\prime} w^{\prime}}$, vertical velocity skewness $\overline{w^{\prime} w^{\prime} w^{\prime}} / \overline{w^{\prime} w^{\prime}}$, and buoyancy flux $\rho c_{p} \overline{w^{\prime} \theta_{v}^{\prime}}$. The plus signs represent mean cloud base and cloud top.

in Fig. 11. Boundary layer depth also influences the $\overline{w^{\prime} w^{\prime}}$ maximum through the vertical distance over which the buoyancy generation mechanism acts: all else being equal, a deeper boundary layer will exhibit a greater maximum in $\overline{w^{\prime} w^{\prime}}$

Profiles of skewness (Fig. 12) are positive everywhere, consistent with smaller, more intense updrafts, and larger, weaker downdrafts. Positive skewness implies a circulation driven in a bottom-up fashion, predominantly by convection rooted in the surface layer. The tendency of the vertical velocity field to be positively skewed in strongly precipitating stratocumulus-topped boundary layers is well known (e.g., Stevens et al. 1998; Ackerman et al. 2009), a behavior that is also evident in trade cumulus boundary layers (Siebesma et al. 2003; van Zanten et al. 2011). All four simulations are positively skewed, although there is a tendency for the skewness in the deeper cases to be greater.

The buoyancy flux is predominantly positive over the depth of the boundary layer, except for the layer of negative flux near the inversion and a very shallow layer in the doubled CCN simulation at $z=0.5 \mathrm{~km}$. Previous work showed that, most often, the decoupling of the cloud and subcloud properties evinced in the mean profiles is accompanied by negative buoyancy fluxes and a minimum in vertical velocity variance at cloud base (e.g., Ackerman et al. 2009). The VOCALS simulations, on the other hand, exhibit no cloud-base minimum in $\overline{w^{\prime} w^{\prime}}$, and the buoyancy flux is (nearly) uniformly positive. The main difference between simulations is the magnitude of positive buoyancy flux. The maxima of buoyancy flux are greater in the deeper cases, meaning that the buoyancy generation of TKE is greater in these simulations. From the positive skewness and buoyancy flux we may infer that the updrafts are, at least in the mean sense, always positively buoyant and never have to do work against the mean stratification. That is, the circulation is always associated with a transfer of potential energy (associated with parcels based in the subcloud layer) into kinetic energy. Similarly, downdrafts are negatively buoyant on average, although the positive skewness indicates that the circulation is updraft-dominant. A comparison of Table 1 and Fig. 12 illustrates that entrainment rate increases with increasing integrated buoyancy flux (as in Caldwell and Bretherton 2009), which gives us some confidence that the model's entrainment rate behavior is reasonable (even though the entrainment rates themselves are too large).

\section{b. Statistical distributions}

The C-band radar on the $R H B$ can provide constraints on the control (Deep) simulation. Figure 13 compares radar reflectivity PDFs of the four simulations, with the

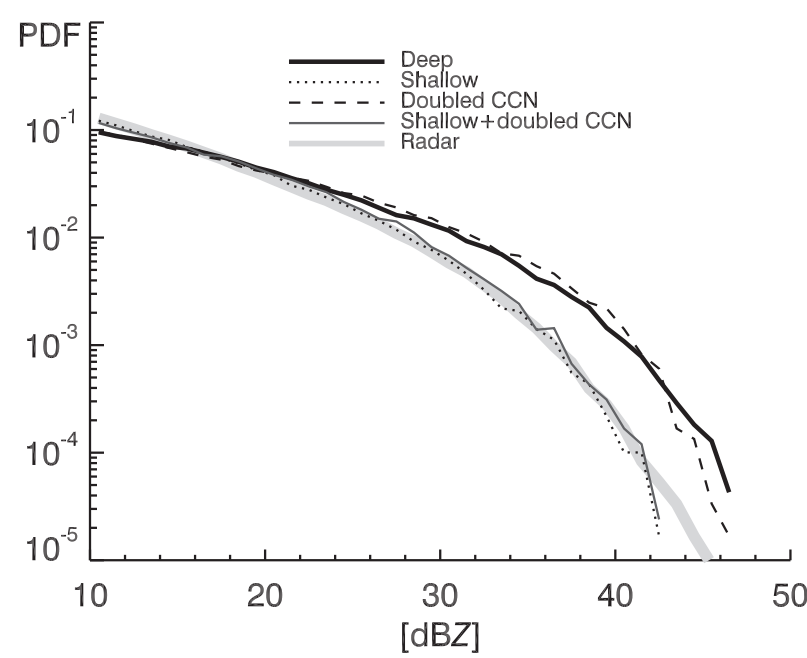

FIG. 13. Normalized frequency distribution (PDF) of reflectivity calculated at a constant height of $490 \mathrm{~m}$, taken over the 4-h period $(8-12 \mathrm{~h})$. Units are fraction per $\mathrm{dBZ}$. 

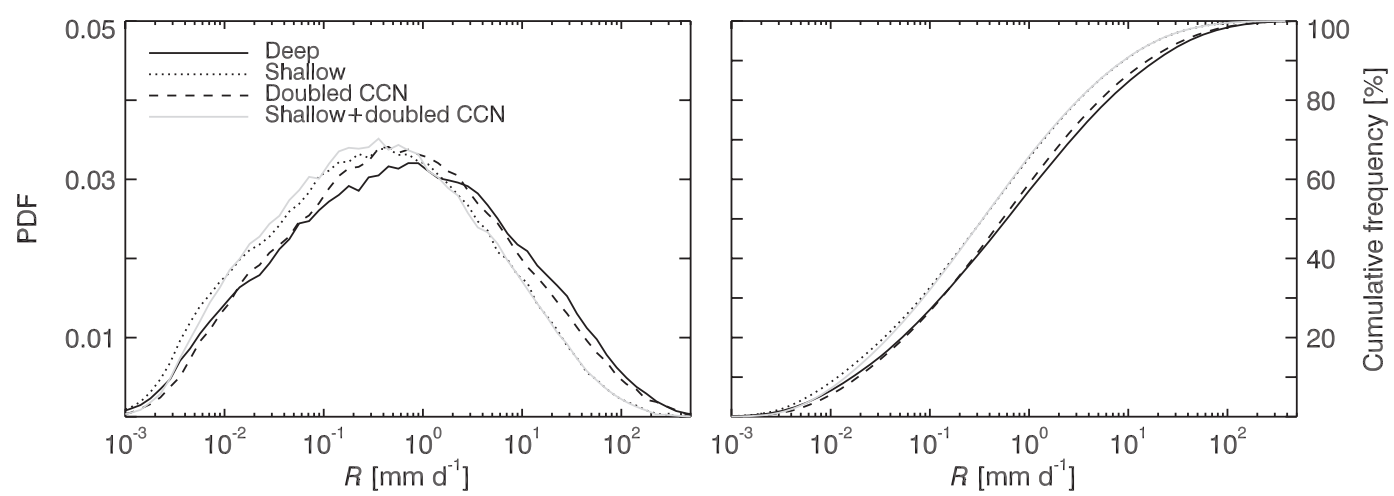

FIG. 14. Cumulative and normalized frequency distribution (PDF) of surface precipitation rate, calculated over the last $4 \mathrm{~h}$ of the simulations.

reflectivity PDF from the $R H B$ from (corresponding to the strong drizzle case from 0900 to 1700 UTC) overlaid. The figure compares reflectivity PDFs taken at a constant height of $490 \mathrm{~m}$. In the model, reflectivity is calculated as the sixth moment of the drop size distribution over the 4-h period (8-12 h). The observational PDF is calculated over the period 0900-1700 UTC, over which the linear feature in Fig. 1 is present. A reflectivity threshold of $-10 \mathrm{dBZ}$ is applied prior to calculating the PDF from the simulation output. This threshold roughly corresponds to the sensitivity of the C-band radar in the immediate vicinity of the ship.

Comparing model-calculated reflectivity with observations is fraught with challenges. Most fundamentally, the model-derived reflectivity is a point calculation, which neglects subgrid-scale variability in drop spectra that is captured by the volume sampling of the radar. The radar sampling volume increases with range, whereas the model grid size is consistent over the domain (except for the stretched vertical grid). The caveats about comparing observed and simulated reflectivity notwithstanding, the simulated reflectivity PDFs agree surprisingly well with the PDF calculated from observed reflectivity (Fig. 13). Ideally, the Deep (control) simulation would exhibit the best agreement with the observations, but given the idealized nature of the simulations and the difficulties with comparing observed and model-derived reflectivities, the agreement between simulated reflectivity and the observations is remarkable. All four simulations exhibit similar distributions for reflectivities up to approximately $28 \mathrm{dBZ}$. Above this threshold the distributions diverge. The simulations, particularly the shallow cases, capture the observed occurrence of reflectivity greater than $30 \mathrm{dBZ}$.

PDFs of surface precipitation rate (Fig. 14) indicate contributions of showery precipitation consistent with the reflectivity PDFs. The precipitation PDFs exhibit lognormal behavior, with the modal values ranging from 0.3 to $1.0 \mathrm{~mm}$ day $^{-1}$ consistent with the mean $R$ values in
Table 1. The cumulative distributions further illustrate the relative contribution from large precipitation rates. For the control simulation, precipitation rates greater than $1 \mathrm{~mm} \mathrm{day}^{-1}$ contribute $43 \%$ of the precipitation, and rates greater than $10 \mathrm{~mm}$ day $^{-1}$ contribute $15 \%$. Rates greater than $100 \mathrm{~mm}$ day $^{-1}$ contribute a small but nonnegligible fraction (2\%) of the total precipitation.

To more completely characterize the statistical distribution of the model reflectivity, we calculate contoured frequency by altitude diagrams (CFADs; Yuter and Houze 1995) for the four simulations (Fig. 15). The CFADs include the entire range of simulated reflectivity from -40 to $50 \mathrm{dBZ}$, ranging well below the sensitivity of the $R H B$ radar. CFADs from all four cases are superficially quite similar. The consistency of the modal reflectivity $(\sim-10 \mathrm{dBZ}$ in all the cases) is consistent with the similarity in the liquid water content and other thermodynamic profiles in Fig. 11. The increase with height of the modal reflectivity indicated by the dashed line on the Deep simulation panel corresponds to the increase in liquid water content (mostly via droplet size) with height in updrafts. Because many of these updraft structures are reminiscent of trade cumulus updrafts, we anticipate that their liquid water content values are substantially subadiabatic. The reflectivity mode associated with the precipitation core is evident below $0.6 \mathrm{~km}$. For a given drop spectrum, smaller drops are preferentially evaporated as they fall and large drops continue to coagulate, which serves to explain the increases in modal reflectivity as precipitation falls toward the surface, even though the total precipitation decreases.

The most striking difference between the simulations relates to the instances of large values of reflectivity in the distribution tail at each altitude. The reflectivity corresponding to the smallest contour value $\left(10^{-5}\right)$ gives a rough indication of the frequency of occurrence of large reflectivities in each simulation. The largest reflectivity values are slightly less frequent in the Doubled CCN simulation but notably reduced in the two shallow cases. 

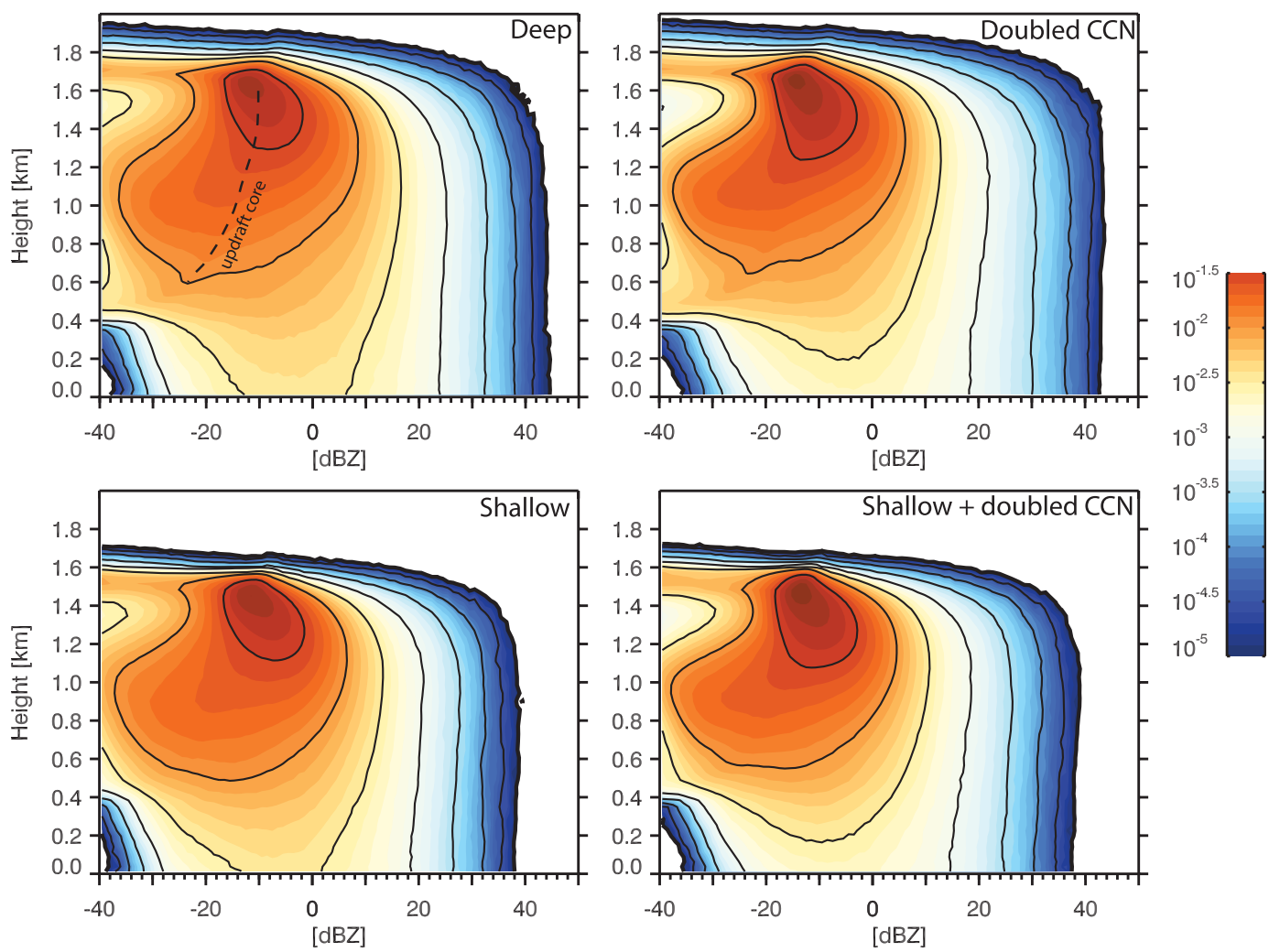

FIG. 15. CFADs of reflectivity for the four simulations. Labels on the color bar correspond to contour values. Contour units are fraction per $\mathrm{dB} Z$.

A major result of this study is that a perturbation to the boundary layer thermodynamics (a $1 \sigma$ or $200-\mathrm{m}$ reduction in depth) has a greater influence on reducing the precipitation than does a $1 \sigma$ change (corresponding in this case to a doubling) in $\mathrm{CCN}$ concentration.
CFADs of the kinematic fields in Fig. 16 are conditionally sampled to include only regions of reflectivity of at least $10 \mathrm{dBZ}$, corresponding to drizzle cells cores, to better compare with the radar-based statistics of SEP drizzling clouds from Comstock et al. (2007). The mode
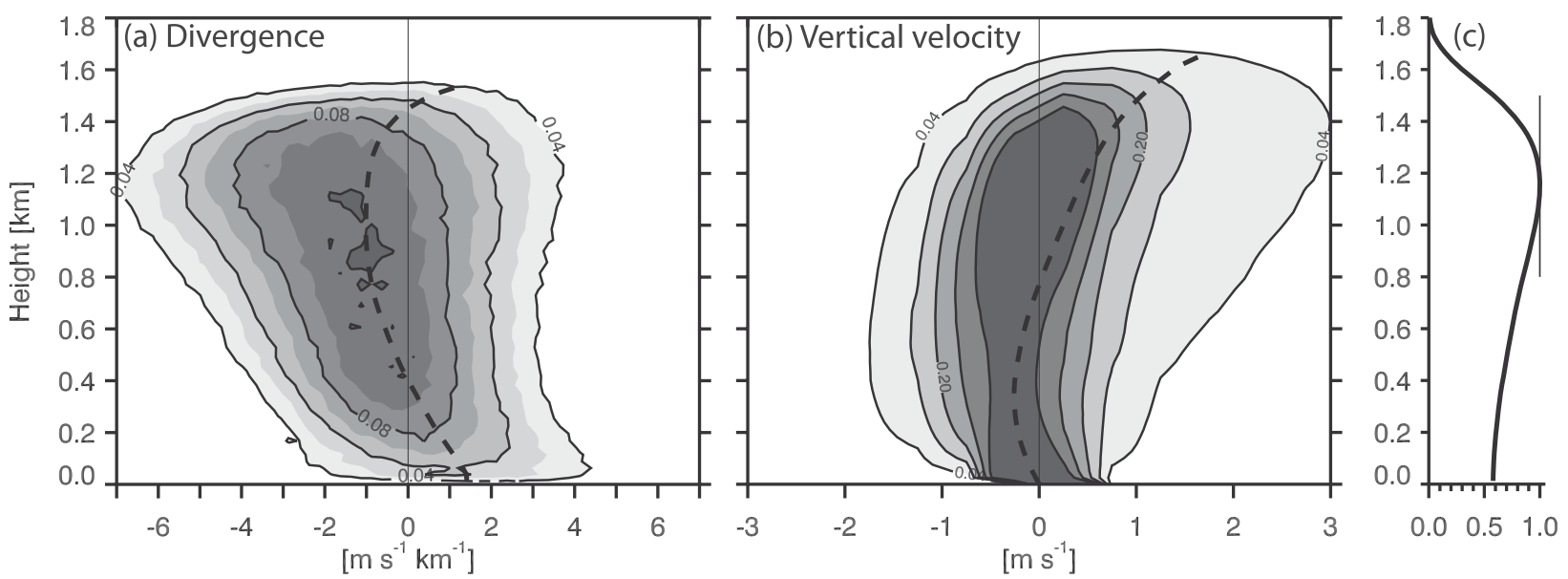

FIG. 16. CFADs of (a) divergence and (b) vertical velocity for the Deep simulation, conditionally sampled in regions of reflectivity $\geq$ $10 \mathrm{dBZ}$. Thick dashed lines represent mean profiles. (c) Profile of the fractional number of points in each level employed in the CFADs, related to the number of points in each level. The difference in topmost height of the CFADs is a result of the choice of contour levels. 
of the divergence distribution in Fig. 16a slants to the left, with the mean profile indicating that the tendency is for convergence to increase with height within the $0.4-1.1-\mathrm{km}$ layer. The distribution mode is most strongly convergent at $1.1 \mathrm{~km}$, just below the altitude of the strongest convergence outliers at $1.2 \mathrm{~km}$. Divergence outliers of similar magnitude occur near the top and the bottom of the boundary layer. The detrainment near the inversion is primarily occurring in echoes less than $10 \mathrm{dBZ}$, which is not present in the distribution. Near the surface, the distribution mode is slightly divergent, and the strongest divergence is about twice as large as the maximum convergence. This structure is consistent with open-cellular category described in Comstock et al. (2007). In particular, the midlevel convergence is a prominent feature of both the model and observations. In this simulation the cloud and subcloud layers are coupled by deep convective circulations, and the wide layer of midlevel convergence is associated with surface-based updrafts ascending into cloud.

The distribution of vertical velocity is by definition consistent with the horizontal divergence but aids in illustrating details of the updraft/downdraft structure. Strong updrafts $\left(>4 \mathrm{~m} \mathrm{~s}^{-1}\right)$ occur at $1.4 \mathrm{~km}$ in altitude, whereas downdrafts are present but tend to be weaker than updrafts $\left(>-2 \mathrm{~m} \mathrm{~s}^{-1}\right)$. The thresholding at $10 \mathrm{dBZ}$ yields modal vertical velocities that are slightly negative. We do not expect to see evaporatively driven cold pools in this distribution because their associated reflectivities are less than $10 \mathrm{dBZ}$. The positive skewness of the vertical velocity distribution implies the prevalence of updrafts over downdrafts.

\section{Discussion and conclusions}

We performed a series of simulations based on observations of strongly drizzling boundary layer cells observed during the VOCALS field campaign in order to address our motivating question. Specifically, we asked which exerts greater control on boundary layer precipitation outcomes, thermodynamic properties (specifically in the form of boundary layer depth) or aerosol. The control case was based on field observations taken from the $R H B$. The sensitivity simulations were constrained by the variability in boundary layer depth and CCN concentration observed over the course of the field project.

Both thermodynamic and $\mathrm{CCN}$ perturbations influence precipitation processes, but our findings indicate that the sensitivity to thermodynamic changes dominates, at least for the short-term sensitivity explored here. The deeper boundary layer produces greater liquid water content and more precipitation. Heavier precipitation tends to stabilize the boundary layer to a greater degree than lighter precipitation. Increased aerosol concentration primarily affects the timing of precipitation rather than precipitation rate. Longer-term feedbacks may be different because boundary layer cloud feedbacks may often be damped or buffered (Stevens and Feingold 2009).

Our conclusions about the relative sensitivity of the two perturbations are similar to those reached by Wang et al. (2010). Although both studies are based on VOCALS, we assume environmental characteristics from farther west in the region when the $R H B$ was located at approximately $85^{\circ} \mathrm{W}$. Thermodynamically, the boundary layer we simulated was deeper than the Wang et al. case (centered at $80^{\circ} \mathrm{W}$ ), contained anomalously stronger precipitation cells, and was stratified to a greater degree. The two studies thus explore different regions of the SEP parameter space.

In addition to addressing the primary question, our results speak to dynamical and precipitation processes in a highly stably stratified boundary layer. Negative buoyancy arising from cloud-top longwave cooling doubtless contributes to the buoyancy generation of TKE; however, we find that the boundary layer circulation is dominated by a relatively few number of strong couplets composed of buoyant updrafts and precipitation-laden downdrafts. The strongest local precipitation rates and the largest reflectivity values are associated with these cells.

The term "decoupled" might apply to our simulated boundary layer, yet this term is fraught with much ambiguity. When is a boundary layer decoupled? Is it sufficient that the mean thermodynamic properties of the cloud and subcloud layers differ? Must a minimum in cloud-base $\overline{w^{\prime} w^{\prime}}$ or negative buoyancy flux be present? Is either condition sufficient to classify a boundary layer as decoupled, or are both conditions necessary? The large degree of stratification in our VOCALS simulation is consistent with the view of decoupling defined by thermodynamic stratification but does not satisfy the dynamical requirements. Yet it is clear that the two layers are coupled, perhaps intermittently, in the sense that strong convective updrafts provide the source of moisture to the cloud layer. Hence, even if the overturning of the boundary layer is insufficient to mix out the stable stratification, the subcloud and cloud layers nevertheless communicate via convective updrafts and downdrafts.

The VOCALS boundary layer explored in this study sits in a unique position in the continuum of marine boundary layers (Fig. 17). We show two versions of the profile for VOCALS, one representing the period of strong drizzle on 26 October 2008 and the other scaling the 26 October sounding by the mean boundary layer depth observed by the $R H B$ during the VOCALS cruises. On one side of the continuum, DYCOMS-II RF01 is an 

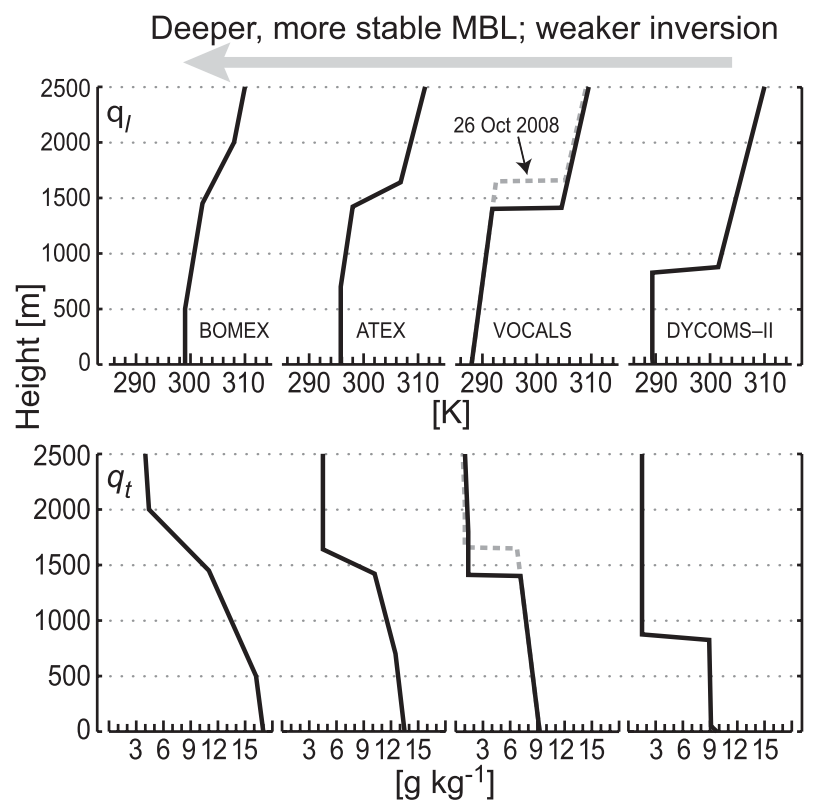

FIG. 17. Conceptual model of the continuum of cloudy boundary layers. From right to left: boundary layer stratocumulus (DYCOMS II); the VOCALS environment at $20^{\circ} \mathrm{S}, 85^{\circ} \mathrm{W}$; trade cumulus rising into a stratocumulus layer (ATEX); and trade cumulus (BOMEX). The dashed lines in the VOCALS profiles represent the strong drizzle case of 26 Oct 2008 that we simulate. The solid lines represent the 26 Oct sounding scaled by the mean boundary layer depth observed during VOCALS.

archetypical marine boundary layer topped by stratocumulus (Stevens et al. 2005a). The DYCOMS-II boundary layer is characterized by fairly shallow, nearly well-mixed boundary layers with large jumps at cloud top. On the other end lie the trade cumulus cases of the Barbados Oceanographic and Meteorological Experiment (BOMEX; Siebesma et al. 2003) or RICO (van Zanten et al. 2011). Trade cumulus boundary layers contain a well-mixed subcloud layer and a thermodynamically stratified cloud layer topped by the trade inversion. Between these two extremes of the continuum lies the regime where trade cumulus clouds rise into a deck of stratocumulus. ATEX (Stevens et al. 2001) provides a good example of the last type of cloud system, which contains some characteristics both of stratocumulus and trade cumulus. More stable and deeper boundary layers populate the right side of the continuum; more well-mixed and shallower boundary layers lie to the left. The vertical structure of the VOCALS boundary layer, particularly the variation of thermodynamic structure in the vertical, bears greatest resemblance to ATEX. VOCALS is cooler and drier than ATEX and is topped by a sharper inversion. In a geographical sense, the continuum represents an idealized transition from eastern subtropical oceans (DYCOMS-II) toward the west and equatorward (BOMEX).
The conceptual model of Wyant et al. (1997) ascribes this transition predominantly to a deepening and decoupling of the boundary layer stemming from moving over warmer SSTs. But many modeling studies (e.g., Stevens et al. 1998) have demonstrated that precipitation can also result in thermodynamic stratification and decoupling. The relative importance of precipitation and SST gradient mechanisms in producing the continuum in Fig. 17 is not well understood and would be a fruitful topic for further pursuit.

Acknowledgments. Thanks to Marat Kharioutdinov for making available the SAM model to the scientific community and to Yefim Kogan for ongoing advice and collaborations. Dave Covert supplied the $\mathrm{CCN}$ data. Thanks to Qiang Fu for the use of his radiation code. Thanks to Rob Wood for the NCEP analysis data. Special thanks go to Chris Fairall, Dan Wolfe, Sergio Pezoa, Matthew Miller, and Justin Crouch for running and monitoring C-band radar operations during the VOCALS cruises and to Christina Aldereguia, Angel Adames, Monica Laureno, and Casey Burleyson for radar data processing and analysis. Beth Tully refined some of the figures. Some of the computing for this project was performed at the OU Supercomputing Center for Education and Research (OSCER) at the University of Oklahoma. We appreciate the thoughtful comments from three anonymous reviewers. This investigation was supported by the University of Kansas General Research Fund allocation 230211 and New Faculty Startup funds, and U.S. National Oceanic and Atmospheric Administration (NOAA) Climate Program Office (CPO) Climate Prediction Program for the Americas (CPPA) Grants GC09-252b, GC09-507, and NA10OAR4310160.

\section{REFERENCES}

Ackerman, A. S., and Coauthors, 2009: Large-eddy simulations of a drizzling, stratocumulus-topped marine boundary layer. Mon. Wea. Rev., 137, 1083-1110.

Albrecht, B. A., 1989: Aerosols, cloud microphysics, and fractional cloudiness. Science, 245, 1227-1230.

Bony, S., and J. Dufresne, 2005: Marine boundary layer clouds at the heart of tropical cloud feedback uncertainties in climate models. Geophys. Res. Lett., 32, L20806, doi:10.1029/ 2005 GL023851.

Bretherton, C. S., and Coauthors, 1999: An intercomparison of radiatively driven entrainment and turbulence in a smoke cloud, as simulated by different numerical models. Quart. J. Roy. Meteor. Soc., 125, 391-423.

— , and Coauthors, 2004: The EPIC 2001 stratocumulus study. Bull. Amer. Meteor. Soc., 85, 967-977.

Caldwell, P., and C. S. Bretherton, 2009: Large eddy simulation of the diurnal cycle in southeast Pacific stratocumulus. J. Atmos. Sci., 66, 432-449. 
$-1-$, and R. Wood, 2005: Mixed-layer budget analysis of the diurnal cycle of entrainment in southeast Pacific stratocumulus. J. Atmos. Sci., 62, 3775-3791.

Comstock, K. K., C. S. Bretherton, and S. E. Yuter, 2005: Mesoscale variability and drizzle in southeast Pacific stratocumulus. J. Atmos. Sci., 62, 3792-3807.

— S. E. Yuter, R. Wood, and C. S. Bretherton, 2007: The threedimensional structure and kinematics of drizzling stratocumulus. Mon. Wea. Rev., 135, 3767-3784.

Dearden, C., 2009: Investigating the simulation of cloud microphysical processes in numerical models using a one-dimensional dynamical framework. Atmos. Sci. Lett., 10, 207-214.

Deardorff, J. W., 1980: Stratocumulus-capped mixed layers derived from a three-dimensional model. Bound.-Layer Meteor., 18, 495-527.

de Szoeke, S. P., C. W. Fairall, D. E. Wolfe, L. Bariteau, and P. Zuidema, 2010a: Surface flux observations on the southeastern tropical Pacific Ocean and attribution of SST errors in coupled ocean-atmosphere models. J. Climate, 23, 4152-4174.

— , S. E. Yuter, P. Zuidema, C. W. Fairall, and W. A. Brewer, 2010b: Ship-based observation of drizzling stratocumulus clouds from EPIC to VOCALS. CLIVAR Exchanges, No. 39, International CLIVAR Project Office, Southampton, United Kingdom, 11-13.

Feingold, G., and S. M. Kreidenweis, 2002: Cloud processing of aerosol as modeled by a large eddy simulation with coupled microphysics and aqueous chemistry. J. Geophys. Res., 107, 4687, doi:10.1029/2002JD002054.

,-- B. Stevens, and W. R. Cotton, 1996: Numerical simulations of stratocumulus processing of cloud condensation nuclei through collision-coalescence. J. Geophys. Res., 101, 21 391-21 402.

- W. L. Eberhard, D. E. Veron, and M. Previdi, 2003: First measurements of the Twomey indirect effect using ground-based remote sensors. Geophys. Res. Lett., 30, 1287, doi:10.1029/ 2002 GL016633.

-, R. Furrer, P. Pilewskie, L. A. Remer, Q. Min, and H. Jonsson, 2006: Aerosol indirect effects at Southern Great Plains during the May 2003 intensive operations period. J. Geophys. Res., 111, D05S14, doi:10.1029/2004JD005648.

Frisch, A. S., C. W. Fairall, and J. B. Snider, 1995: Measurement of stratus cloud and drizzle parameters in ASTEX with a $\mathrm{K}_{\alpha}$-band Doppler radar and a microwave radiometer. J. Atmos. Sci., 52 , 2788-2799.

Fu, Q., and K. N. Liou, 1992: On the correlated $k$-distribution method for radiative transfer in nonhomogeneous atmospheres. J. Atmos. Sci., 49, 2139-2156.

- , and 1993: Parameterization of the radiative properties of cirrus clouds. J. Atmos. Sci., 50, 2008-2025.

Garreaud, R. D., and R. Muñoz, 2004: The diurnal cycle in circulation and cloudiness over the subtropical southeast Pacific: A modeling study. J. Climate, 17, 1699-1710.

Garrett, T. J., and P. V. Hobbs, 1995: Long-range transport of continental aerosols over the Atlantic Ocean and their effects on cloud structures. J. Atmos. Sci., 52, 2977-2984.

Houze, R. A., S. A. Rutledge, M. I. Biggerstaff, and B. F. Smull, 1989: Interpretation of Doppler weather radar displays of midlatitude mesoscale convective systems. Bull. Amer. Me teor. Soc., 70, 608-619.

Hudson, J. G., 1993: Cloud condensation nuclei near marine cumulus. J. Geophys. Res., 98, 2693-2702.

Khairoutdinov, M. F., and Y. L. Kogan, 1999: A large eddy simulation model with explicit microphysics: Validation against aircraft observations of a stratocumulus-topped boundary layer. J. Atmos. Sci., 56, 2115-2131.

—, and D. A. Randall, 2003: Cloud resolving modeling of the ARM summer 1997 IOP: Model formulation, results, uncertainties, and sensitivities. J. Atmos. Sci., 60, 607-625.

Klein, S. A., and D. L. Hartmann, 1993: The seasonal cycle of low stratiform clouds. J. Climate, 6, 1587-1606.

Kogan, Y. L., 1991: The simulation of a convective cloud in a 3-D model with explicit microphysics. Part I: Model description and sensitivity experiments. J. Atmos. Sci., 48, 1160-1189.

, M. P. Khairoutdinov, D. K. Lilly, Z. N. Kogan, and Q. Liu, 1995: Modeling of stratocumulus cloud layers in a large eddy simulation model with explicit microphysics. J. Atmos. Sci., 52, 2923-2940.

Larson, V. E., K. E. Kotenberg, and N. B. Wood, 2007: An analytic longwave radiation formula for liquid layer clouds. Mon. Wea. Rev., 135, 689-699.

Mechem, D. B., P. C. Robinson, and Y. L. Kogan, 2006: Processing of cloud condensation nuclei by collision-coalescence in a mesoscale model. J. Geophys. Res., 111, D18204, doi:10.1029/ 2006JD007183.

Medeiros, B., B. Stevens, I. M. Held, M. Zhao, D. L. Williamson, J. G. Olson, and C. S. Bretherton, 2008: Aquaplanets, climate sensitivity, and low clouds. J. Climate, 21, 4974-4991.

Paluch, I. R., and D. H. Lenschow, 1991: Stratiform cloud formation in the marine boundary layer. J. Atmos. Sci., 48, 21412158.

Savic-Jovcic, V., and B. Stevens, 2008: The structure and mesoscale organization of precipitating stratocumulus. J. Atmos. Sci., 65, $1587-1605$

Siebesma, A. P., and Coauthors, 2003: A large eddy simulation intercomparison study of shallow cumulus convection. J. Atmos. Sci., 60, 1201-1219.

Smolarkiewicz, P. K., and W. W. Grabowski, 1990: The multidimensional positive definite advection transport algorithm: Non-oscillatory option. J. Comput. Phys., 86, 355-375.

Stein, U., and P. Alpert, 1993: Factor separation in numerical simulations. J. Atmos. Sci., 50, 2107-2115.

Stevens, B., and A. Seifert, 2008: Understanding macrophysical outcomes of microphysical choices in simulations of shallow cumulus convection. J. Meteor. Soc. Japan, 86A, 143-162.

, and G. Feingold, 2009: Untangling aerosol effects on clouds and precipitation in a buffered system. Nature, 461, 607-613, doi:10.1038/nature08281.

, W. R. Cotton, G. Feingold, and C.-H. Moeng, 1998: Large-eddy simulations of strongly precipitating, shallow, stratocumulustopped boundary layers. J. Atmos. Sci., 55, 3616-3638.

-, and Coauthors, 2001: Simulations of trade wind cumuli under a strong inversion. J. Atmos. Sci., 58, 1870-1891.

- and Coauthors, 2003: Dynamics and chemistry of marine stratocumulus-DYCOMS-II. Bull. Amer. Meteor. Soc., 84, $579-593$.

— , and Coauthors, 2005a: Evaluation of large-eddy simulations via observations of nocturnal marine stratocumulus. Mon. Wea. Rev., 133, 1443-1462.

- , G. Vali, K. Comstock, R. Wood, M. C. van Zanten, P. H. Austin, C. S. Bretherton, and D. H. Lenschow, 2005b: Pockets of open cells and drizzle in marine stratocumulus. Bull. Amer. Meteor. Soc., 86, 51-57.

Twomey, S., 1974: Pollution and the planetary albedo. Atmos. Environ., 8, 1251-1256.

1977: The influence of pollution on the shortwave albedo of clouds. J. Atmos. Sci., 34, 1149-1152. 
van Zanten, M. C., and Coauthors, 2011: Controls on precipitation and cloudiness in simulations of trade-wind cumulus as observed during RICO. J. Adv. Model. Earth Syst., 3, M06001, doi:10.1029/2011MS000056.

Wang, H., and G. Feingold, 2009a: Modeling mesoscale cellular structures and drizzle in marine stratocumulus. Part I: Impact of drizzle on the formation and evolution of open cells. J. Atmos. Sci., 66, 3237-3256.

— drizzle in marine stratocumulus. Part II: The microphysics and dynamics of the boundary region between open and closed cells. J. Atmos. Sci., 66, 3257-3275.

, ——, R. Wood, and J. Kazil, 2010: Modelling microphysical and meteorological controls on precipitation and cloud cellular structures in southeast Pacific stratocumulus. Atmos. Chem. Phys., 10, 6347-6362.

Wood, R., 2006: Rate of loss of cloud droplets by coalescence in warm clouds. J. Geophys. Res., 111, D21205, doi:10.1029/ 2006JD007553.

, M. Köhler, R. Bennartz, and C. O'Dell, 2009: The diurnal cycle of surface divergence over the global oceans. Quart. J. Roy. Meteor. Soc., 135, 1484-1493.

, and Coauthors, 2011: The VAMOS Ocean-Cloud-AtmosphereLand Study Regional Experiment (VOCALS-REx): Goals, platforms, and field operations. Atmos. Chem. Phys., 11, 627-654.

Wyant, M. C., C. S. Bretherton, H. A. Rand, and D. E. Stevens, 1997: Numerical simulations and a conceptual model of the stratocumulus to trade cumulus transition. J. Atmos. Sci., 54, 168-192.

— , and Coauthors, 2010: The PreVOCA experiment: Modeling the lower troposphere in the southeast Pacific. Atmos. Chem. Phys., 10, 4757-4774.

Xue, H., G. Feingold, and B. Stevens, 2008: Aerosol effects on clouds, precipitation, and the organization of shallow cumulus convection. J. Atmos. Sci., 65, 392-406.

Yuter, S. E., and R. A. Houze Jr., 1995: Three-dimensional kinematic and microphysical evolution of Florida cumulonimbus. Part II: Frequency distribution of vertical velocity, reflectivity, and differential reflectivity. Mon. Wea. Rev., 123, 1941-1963.

_ , Y. L. Serra, and R. A. Houze Jr., 2000: The 1997 Pan American Climate Studies Tropical Eastern Pacific Process Study. Part II: Stratocumulus region. Bull. Amer. Meteor. Soc., 81, 483-490.

Zipser, E. J., 1977: Mesoscale and convective-scale downdrafts as distinct components of squall-line circulation. Mon. Wea. Rev., 105, 1568-1589. 